Portland State University

PDXScholar

$11-4-1994$

\title{
Women who Select Naturopathic Health Care During the Menopausal Transition: A Study in Grounded Theory
}

Dorothy S. Tibbetts

Portland State University

Follow this and additional works at: https://pdxscholar.library.pdx.edu/open_access_etds

Part of the Health and Physical Education Commons

Let us know how access to this document benefits you.

\section{Recommended Citation}

Tibbetts, Dorothy S., "Women who Select Naturopathic Health Care During the Menopausal Transition: A Study in Grounded Theory" (1994). Dissertations and Theses. Paper 4879.

https://doi.org/10.15760/etd.6755

This Thesis is brought to you for free and open access. It has been accepted for inclusion in Dissertations and Theses by an authorized administrator of PDXScholar. Please contact us if we can make this document more accessible: pdxscholar@pdx.edu. 


\section{THESIS APPROVAL}

The abstract and thesis of Dorothy S. Tibbetts for the Master of Science in Health Education were presented November 4, 1994, and accepted by the thesis committee and the department.

\section{COMMTTTEE APPROVALS:}
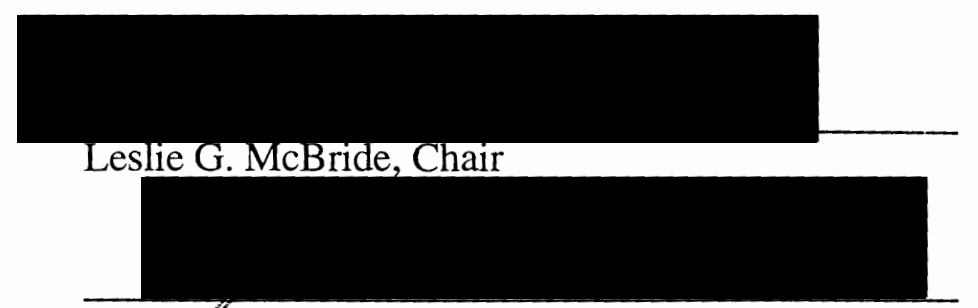

Judy Søgel

DEPARTMENT APPROVAL:
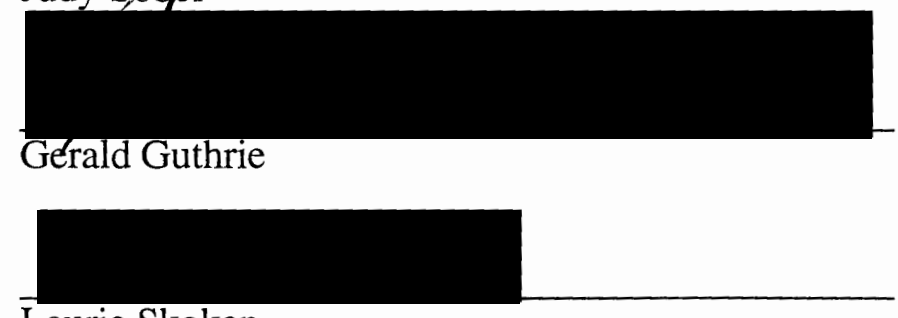

Laurie Skokan

Representative of the Office of Graduate Studies

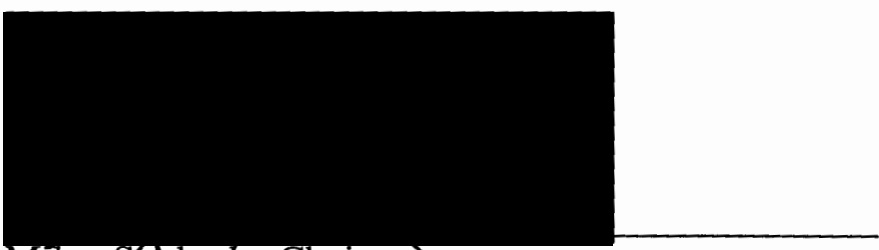

Mhian sseboda, Chair<smiles>[14CH3]</smiles>

$* * * * * * * * * * * * * * * * * * * * * * * * * * * * * * * * * * * * * * * * * * * * * * * *$

ACCEPTED FOR PORTLAND STATE UNIVERSITY BY THE LIBRARY

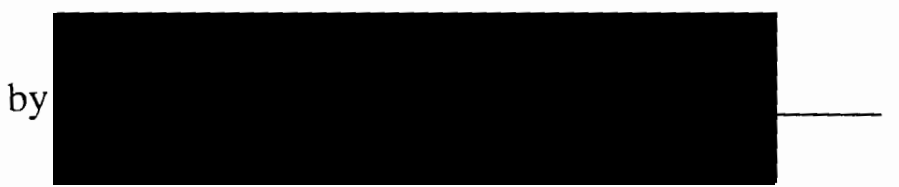

on

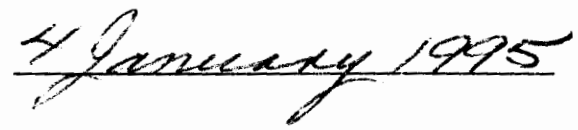




\begin{abstract}
An abstract of the thesis of Dorothy S. Tibbetts for the Master of Science in Health Education presented November 4, 1994.
\end{abstract}

Title: Women who select naturopathic health care during the menopausal transition: A study in grounded theory.

A grounded theory method was used to investigate the experiences of women who use naturopathic medicine, a system of alternative therapy, for health care during the menopausal transition. Transcripts of 16 in-depth interviews with women who received naturopathic health care during the menopausal transition were analyzed with respect to three research questions: (a) Why do women seek naturopathic health care during the menopausal transition? (b) Do women who use naturopathic treatment for menopausal health care share similar experiences of menopause? and (c) Are women satisfied with the naturopathic treatment they receive for menopausal health care?

Conditions leading to informants' use of naturopathy were represented by two categories: Practicing natural self-care, and Rejecting the conventional medical system. Experiences of menopause were represented by three categories: It's not a singular event, Paying attention to changes in and around me, and Information helps. Informants' satisfaction with naturopathy for menopause-related health care was represented by four categories: Naturopathy is consistent with engaging in natural self-care practices, Naturopathy is effective in treating troubling menopausal signs, Naturopathy addresses individual and interrelated aspects of menopause, and Naturopathy provides moral and informational support. Continued analysis of the data revealed a core category, 
Exchanging information, that provided a foundation for the theoretical model representing the experience of women who use naturopathic health care at menopause.

The grounded theory developed in this study may be useful to health professionals by increasing understanding of the naturopathic health care option for menopausal women. Suggestions for further study include quantitative evaluation of components of the theory developed in this study, continued qualitative and quantitative investigation of aspects of information exchange between patients and their conventional and alternative practitioners, application of grounded theory methodology to studies of women's use of hormone replacement therapy, and application of grounded theory methodology to studies of patients' selection of alternative medicine for health matters other than menopause. 
WOMEN WHO SELECT NATUROPATHIC HEALTH CARE DURING THE MENOPAUSAL TRANSITION: A STUDY IN GROUNDED THEORY

by

DOROTHY S. TIBBETTS

A thesis submitted in partial fulfillment of the requirements for the degree of

MASTER OF SCIENCE
in
HEALTH EDUCATION

Portland State University

1994 


\section{ACKNOWLEDGEMENTS}

I wish to express my gratitude to my advisor, Dr. Leslie McBride, for her continued guidance throughout the course of this investigation. She showed me what was possible and encouraged my best efforts. She will remain an inspiration to me throughout my career as a student and a teacher.

I would like to thank Dr. Tori Hudson of the National College of Naturopathic Medicine. Her assistance was instrumental to the completion of this project.

I am grateful for the support I received from the members of my thesis committee: Dr. Judy Sobel, Dr. Gerald Guthrie, and Dr. Laurie Skokan. Thank-you.

Finally, my special thanks to the women who participated in the study. You generously revealed a private part of your life so that other women might benefit from your experience. 


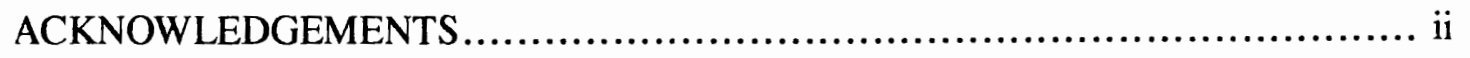

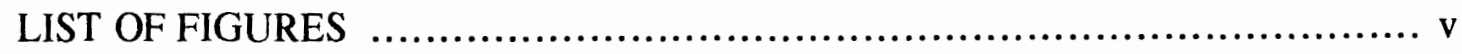

\section{CHAPTER}

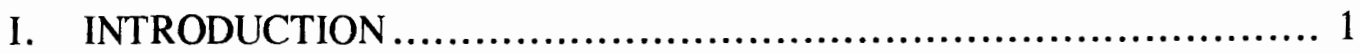

II. LITERATURE REVIEW ........................................... 4

Alternative Medicine ............................................ 5

Definition of Alternative Medicine

Utilization of Alternative Medicine

Evaluation of Alternative Medicine

Menopause ......................................................... 12

The Biomedical Perspective of Menopause

The Sociocultural Perspective of Menopause

The Women's Health Movement Perspective of Menopause

Menopause and Naturopathic Medicine................................... 29

Summary of Literature Review ...................................... 31

Summary of Current Trends in Research and Theory about Alternative Medicine

Summary of Current Trends in Research and Theory about Menopause

Statement of Problem .............................................. 33

III. METHOD …........................................................... 35

Evaluation of Alternative Medicine .................................. 35

Evaluation of Menopause Experience................................. 37

Research Design.............................................. 40

Selection of Informants

Data Collection 


\section{Data Analysis \\ Trustworthiness \\ Limitations \\ Delimitations \\ Point of View}

IV. RESULTS

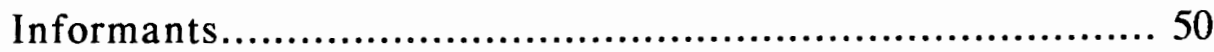

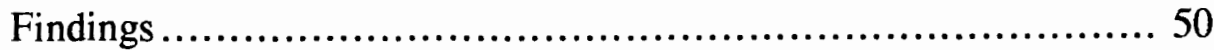

Why do Women Seek Naturopathic Health Care During the Menopausal Transition?

Do Women who use Naturopathic Treatment for Menopausal Health Care Share Similar Experiences of Menopause?

Are Women Satisfied with the Naturopathic Treatment they Receive for Menopausal Health Care?

The Experience of Women who Choose Naturopathic Health Care During the Menopausal Transition: An Integrated Perspective

Core category: Exchanging Information

Narrative Layout of the Grounded Theory

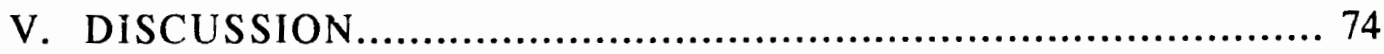

Altemative Medicine ............................................ 75

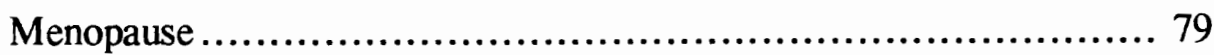

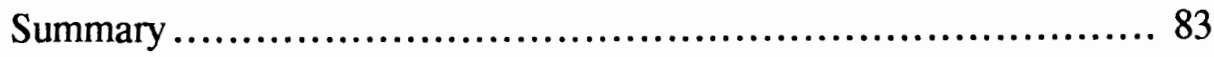

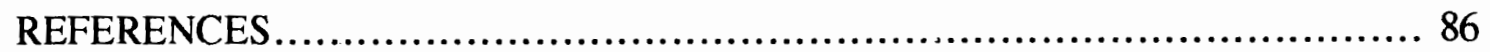

\section{APPENDICES}

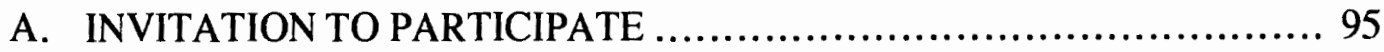

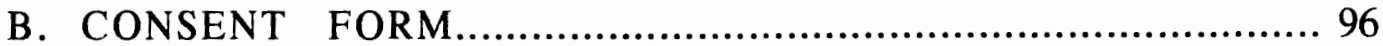

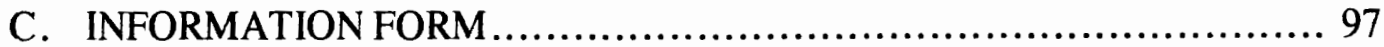

D. INITIAL INTERVIEW GUIDE............................................. 98

E. FINAL INTERVIEW GUIDE.............................................. 100 


\section{LIST OF FIGURES}

FIGURE

PAGE

1. Informant characteristics...................................................... 51

2. Categories and subcategories as they pertain to the three areas of inquiry

3. Sequences of experiences pertaining to conditions leading to the use of naturopathic treatment for menopause-related health care.

4. The experience of women who choose naturopathic health care during the menopausal transition: An integrated perspective 68

5. Women who use naturopathy at menopause: Exchanging information 70 


\section{CHAPTER I}

\section{INTRODUCTION}

The United States is experiencing an unprecedented increase in the utilization of alternative health care systems such as naturopathy, acupuncture, and chiropractic. A 1993 study (Eisenberg et al.) found that in a nationwide survey, one in three adults reported using at least one unconventional therapy in the past year. There is growing awareness within the medical establishment that, because of its emphasis on wellness and prevention, alternative medicine can make a substantial contribution to improved health care delivery in our society (Filips, 1993). Popular media has focused on one large national insurance company's announcement that it will provide coverage for individuals who have a high likelihood of benefiting from "the [Dean] Ornish program" of meditation, vegetarian diet, and imagery for the reversal of heart disease (Filips, 1993; Williams, 1994). Alternative practitioners advocate inclusion of coverage for alternative medicine in the National Health Care policy being formulated by the federal government (O'Neill, 1993). Advocates feel that the preventive focus and typically lower cost of delivery make alternative medicine appropriate for inclusion in a national health plan.

The Eisenberg study (1993) found that alternative therapies are most often used as adjuncts to conventional therapy. It also found that of the $34 \%$ of respondents who had used an unconventional therapy in the past year, $72 \%$ did not discuss this therapy with their regular physician. Clearly, there is a lack of communication not only between conventional and alternative health care providers, but between patients and their physicians as well. 
One means of alleviating this problem is through patient and provider education. The content of this education process can be informed through research into the incentives, attitudes, and beliefs of individuals who choose alternative health care.

There is increasing interest in understanding and evaluating alternative therapies.

The World Health Organization is developing programs designed to incorporate indigenous medical practices into national health services (Akerele, 1987). Osujih (1993) suggests that traditional healers in developing countries can provide inexpensive, socioculturally accessible and acceptable health care alternatives, and that "both systems (orthodox and traditional), should be seen as complementary and supplementary to each other in their respective efforts to protect, promote and maintain the health and well-being of the people” (p. 193). In the United States, the National Institutes of Health were directed by Congress in 1991 to spend two million dollars a year to investigate alternative health care practices (Mervis, 1992). The Office for the Study of Unconventional Medical Practices was established to systematically study the effectiveness of unconventional therapies. It is expected that increased information about alternative medicine, as well as increased understanding of methodological issues that pertain to the evaluation of alternative medicine, will be available in the future (Marwick, 1992).

Jingfeng (1987) suggests that an alternative therapy should be evaluated within the context of the health problem to which it is being applied:

The study and evaluation of AM [(alternative medicine)] should not be performed in a large scale, all-out way, but rather, it should be undertaken on a small scale, disease by disease, with the study step by step extended from a spot to a surface, from easy to difficult. (p. 664)

This study investigates patients' utilization of alternative medicine from the perspective of women seeking naturopathic treatment during their menopausal transition. Menopause provides an appropriate context within which to develop an understanding of 
the utilization of naturopathic medicine for several reasons. Alternative medicine is most often used for nonserious medical conditions (Eisenberg et al., 1993). Menopause is not a life threatening condition, and although it is a unique experience and not representative of other health problems, theory generated from the study of menopause and naturopathic therapy may be useful to future studies concerned with the use of alternative medicine for non-life threatening illnesses. In addition, menopause is a natural part of aging and as such, it raises issues concerned with disease prevention. Alternative medicine is frequently used for disease prevention (Eisenberg et al., 1993); thus, the understanding of the naturopathic approach to menopause- and aging-related disease prevention may be of benefit to understanding other preventive uses for alternative medicine. Further, patients are increasingly demanding physicians who handle patients sensitively and communicate effectively (Clark, 1992). Menopause is representative of health matters that require a sensitive, individualized approach, and the study of menopausal women's selection of naturopathic health care may contribute to the understanding of how an alternative therapy can meet the needs of patients who typically require an individualized approach to treatment.

This study contributes to knowledge about patients' utilization of alternative medicine by investigating the relationship between women's menopausal experience and their decision to seek alternative health care. Interviews with menopausal women are used to develop grounded theory about their use of naturopathic medicine. Through an understanding of the relationship between menopausal experience and naturopathic health care, health educators can assist women in making informed decisions about menopausal health care, and health care providers can better meet the needs of middle-aged women. 


\section{CHAPTER II}

\section{LITERATURE REVIEW}

This review of literature is divided into three sections: (a) alternative medicine, (b) menopause, and (c) the naturopathic approach to menopause. Research conducted on alternative health care has been limited, especially in North America (Sutherland, 1988). Three areas of alternative medicine research emerging from the literature include the definition of alternative medicine, utilization of alternative medicine, and evaluation of alternative medicine.

Following the review of alternative medicine literature will be a review of menopause literature. Biomedical, sociocultural, and Women's Health Movement perspectives of menopause will be outlined. Within each of these sections a review of research that examines women's experience of menopause from the respective point of view will be presented.

Finally, one alternative approach to menopausal health care, naturopathy, will be described. Few studies have been conducted that address women's use of alternative health care during the menopausal transition. Methodological issues relating to both menopause and alternative medicine will be explored further in the method section of this paper. 


\section{Alternative Medicine}

\section{Definition of Alternative Medicine}

Terms used in the literature to identify alternative medicine are not consistent. The term traditional medicine may be employed to reflect the indigenous nature of healing systems that originate in non-Western parts of the world (Jingfeng, 1987). Literature published in England frequently refers to alternative health care as complementary medicine. "'Complementary medicine' indicates approaches which are independent from modern scientific medicine, but have a potential for working with such medicine in a broader context of health care delivery" (Aldridge, 1990, p. 179). More often, the term alternative medicine is used to define any medical approach that is not rooted in scientific medicine (Patel, 1987b). But some researchers (McKee, 1988; Patel, 1987a) point out that many routinely employed modern treatments have never been scientifically tested; thus the terms Western medicine, orthodox medicine, or conventional medicine may be more appropriately used to identify mainstream approaches to health care.

Pietroni (1992) provides a classification system for alternative medicine by separating therapies into four areas: (1) complete systems include homeopathy, osteopathy, herbal medicine, and acupuncture; (2) diagnostic methods include iridology, kinesiology, hair analysis, and aura diagnosis; (3) therapeutic modalities include massage, shiatsu, and reflexology; and (4) self-care approaches include meditation, yoga, relaxation, and dietetics.

Some of the methods that fall into these categories require four years of full time training akin to undergraduate medical school, while others can be learned and applied after a few weekend seminars. It is inappropriate and does reasoned debate an injustice to lump all these categories together under one definition and respond with a prejudiced or enthusiastic stance.

(Pietroni, 1992, p. 564). 
Some researchers define alternative medicines as those therapies that do not follow the allopathic principle of healing which states that if the functioning of the body becomes diseased, a counteracting measure should be used to return the body to normal (Edlin \& Golanty, 1985). Most alternative therapies are guided by the principle that the body contains the power to heal itself, and proactive measures that facilitate self-healing are more appropriate to long term health. These measures are sometimes described as holistic approaches to health care. As applied to alternative medicine, holistic refers to an emphasis on the maintenance of balance between physical, mental, spiritual, social, environmental and emotional dimensions of health. This may also be called a "systems approach" to health care. A systems approach is one in which "all parts of the system--body, mind, spirit, environment, society - are interrelated and interact in such a way as to promote balance within the system. Illness reflects an imbalance between the individual and the wider world" (McKee, 1988, p. 777). Holistic can also be used to describe conventional medicine, however, and this is well illustrated by the emerging field of psychoneuroimmunology, once considered a fringe topic but now legitimized by conventional science through the discovery of "well defined neuroendocrine pathways which are known to link the psyche and the soma" (Baum, 1987).

Although defining alternative medicine is complicated by increasing recognition of psychosocial aspects of illness and use of alternative therapies by mainstream providers of health care, a means of identifying systems of health care selected by patients is necessary. This study will use the terms conventional medicine (CM) and alternative medicine (AM) to describe allopathic and non-allopathic approaches to health care, respectively.

Well-known alternative health care systems include naturopathy, acupuncture, and chiropractic. In addition to systems classified above (Pietroni, 1992), alternative systems also include biofeedback, hypnosis, imagery and visualization, and therapeutic touch. 
Many alternative approaches recognize a metaphysical component of health and, in some cases, an intrinsic or natural life force. Most alternative practitioners stress preventive medicine and patient participation in health maintenance. Naturopathic medicine, an alternative approach to health care that emphasizes prevention, nutrition, and natural therapies, will be described later in this study.

\section{Utilization of Alternative Medicine}

Studies investigating utilization of alternative medicine are concerned with motivating factors associated with patients' selection of alternative health care. Motivating factors include dissatisfaction with conventional medicine; seeking a solution to a health problem; beliefs about health, illness, and treatment; and psychological needs.

Furnham and Smith (1988) studied patients who used homeopathy and concluded that patients select alternative medicine because they are disenchanted with conventional medical practices. This hypothesis is supported by Jensen (1990), who found that the primary motivation of dermatology patients who used alternative medicine was poor results from conventional medicine.

Many studies, however, indicate that patients are not dissatisfied with conventional treatment; rather the primary motivating factor for use of $\mathrm{AM}$ is that patients are seeking a solution to their health problems. Donnelly, Spykerboer, and Thong (1985) found that asthmatic patients who consult alternative medicine practitioners were not disgruntled with conventional medicine and reported high rates of satisfaction with both conventional and alternative medicine. Thomas, Carr, Westlake, and Williams (1991) indicate that $\mathrm{AM}$ is used in Great Britain most frequently as a supplement to conventional medicine, and that most patients continue to use $\mathrm{CM}$ at the same time they use AM. 
The Eisenberg study (1993) found that most people who use alternative medicine do so for nonserious health problems. However, studies of cancer and AIDS (or HIVpositive) patients who use alternative medicine indicate that for serious as well as nonserious health problems, AM utilization is a result of patients' beliefs about illness and treatment. Cassileth, Lusk, Strouse, and Bodenheimer (1984) interviewed cancer patients to find that $54 \%$ of patients using conventional therapy also used unorthodox treatments.

Patients who had used unorthodox therapies differed substantively in their beliefs about illness and treatment from patients using only conventional therapy. Most patients receiving alternative therapies, with or without conventional care, believed that their type of cancer could be prevented, primarily through diet...stress reduction... and environmental changes....These patients believed further that disease in general is caused mainly by poor nutrition, stress, and worry. (p. 110)

In addition, these patients expressed dissatisfaction with conventional practitioners and health care systems, preferred nontoxic regimens, and sought an active role in treatment. In addition, the "quality of patients' relationships with their physicians was related inversely to their propensity to seek unorthodox care" (p. 112).

Northcott and Bachynsky (1993) report that chiropractic patients in Edmonton, Canada use the conventional health care system as much as do non-chiropractic patients. They suggest that interest in chiropractic "seems to reflect a growing public interest in holistic health care, health promotion, disease prevention, and self-care" (p. 434). Murray and Shepherd (1993) concluded that the use of alternative medicine does not lead to a reduction in demand for conventional care. Instead, users of alternative medicine may be more frequent users of conventional medicine, exhibiting a high prevalence of chronic conditions. Lloyd, Lupton, Wiesner, and Hasleton (1993) surveyed 289 patients from eight alternative practices in Sydney, Australia and found that AM patients smoked cigarettes and consumed alcohol less frequently than the population in general. In addition, those surveyed were 
generally critical about the efficacy of allopathic medicine and the manner of [conventional] doctors. They had experienced chronic illness conditions for which allopathic medicine had been unsuccessful in providing relief, and they were generally wary of taking conventional drugs. The respondents valued the holistic approach of the alternative therapist, and the friendly, concerned and detailed attention they received. However, given that many respondents continued to seek attention from general practitioners or medical specialists, it would appear that alternative medicine does not necessarily constitute a replacement for allopathic care, but rather an adjunct sought in times of disenchantment when [conventional] medicine seems not to offer an answer. (p. 143)

In a study that describes the alternative therapies used by HIV-positive patients and those patients' assessments of the efficacy of conventional and alternative therapies, Anderson, O'Connor, MacGregor, and Schwartz (1993) found that $40 \%$ of patients reported having used alternative therapies. Patients' explanatory model of their illness may differ "from what the alternative therapy itself may suggest to the [conventional] clinician....Improved communication on these issues may help prevent therapeutic conflicts, improve effectiveness of care, and better meet patient psychosocial needs" ( $p$. $565)$.

Use of alternative medicine for serious illness raises important ethical issues surrounding choices in health care. Some researchers feel that users of alternative medicine are not adequately informed about biomedical treatments (Montbriand, 1993). Thus, patients' use of AM may preclude use of effective, potentially life-saving conventional treatments. McGinnis (1991) suggests that use of AM causes economic harm to conventional medical research and to patients; direct harm to patients (for example, toxicity deaths related to megavitamin regimens); indirect harm to patients (for example, incorrect diagnosis or guilt associated with self-responsibility principles promoted by AM); and societal harm (for example, increasing popular mistrust of established conventional medical institutions). These issues deserve to be fully addressed from both biomedical and alternative health care perspectives. Such a task, however, is beyond the scope of this 
study. The remainder of this study is concerned with use of AM for non-life-threatening illness and disease prevention.

Sutherland (1988) suggests that a factor influencing utilization of AM is the nature of the illness for which the patient is seeking care. "Patients with either acute benign disease or disease that fits easily into the medical model will be less likely to consider alternative medicine than those with chronic diseases that do not satisfactorily fit the medical model" (p. 1155). Additionally, alternative medicine may be used as a strategy to avoid "unknown long-term dangers of modern medical interventions" (Murray \& Shepherd, 1993, p. 986).

Patients' beliefs about illness and treatment may determine their illness experience, which, in turn, may determine their health care choices:

One of the reasons why so many patients consult both [conventional] doctors and alternative practitioners may result from the phenomenon that [conventional] doctors diagnose and treat diseases as they define them from their biomedical point of view. The patients, however, are concerned with their own particular experience of their illnesses. (Christie, 1991, p. 550)

Patients' beliefs about illness and treatment may also include beliefs about the patientphysician relationship. Aldridge (1990) states that in Europe, where there is a growing movement toward consumer-based medical service, patients choose AM because "the involvement of the patient in his or her own health care is recognized by the [alternative] practitioner" (p. 179). Other reasons for choosing AM are that alternative practitioners have

a psychosocial approach to problems, that the patient's search for health is understood in terms of reasons and intentions, and that there is an acknowledgment of the intent of both parties to cooperate in health care. There is less a turning away from orthodox medical care because of dissatisfaction, more a demand for mixed pluralistic health care. (Aldridge, 1990, p. 179) 
Some researchers suggest that users of AM exhibit greater psychological difficulties than nonusers. Smart, Mayberry, and Atkinson (1986) suggest that patients' use of alternative medicine "results from an attention seeking attitude to their disorder. Alternative medicine practitioners often have long consultation times and adopt an holistic approach to their patients" (p. 828). Furnham and Smith (1988) found that patients of AM exhibit a high frequency of psychological problems. They suggest that

the reason why more disturbed patients visit a homeopath may be because these people are less likely to feel satisfied from a short GP consultation and would prefer the longer sessions available from alternative practitioners. Here an in-depth history and lengthy discussion of their individual problems with emphasis on personal involvement is more likely to suit their needs. (p. 688)

\section{Evaluation of Alternative Medicine}

Until recently, few studies existed that investigated the efficacy of alternative treatments. In 1993 and 1994, however, the National Institutes of Health Office of Alternative Medicine awarded 42 exploratory grants (NIH Office of Alternative Medicine, 1994). These studies are expected to utilize quantitative techniques such as double blind randomized trials (Mahaney, 1992). Although increasing numbers of studies that evaluate the efficacy of many types of alternative treatments can be found in the literature, quantitative evaluation of alternative medicine was not the focus of this study. Therefore, an extensive search for literature concerned with efficacy of AM was not conducted.

Some researchers feel that alternative medicine is difficult to evaluate because factors other than therapeutic intervention may play a role in recovery from illness. "Many medical conditions resolve spontaneously, so that recovery or amelioration of symptoms may be wrongly ascribed to the particular treatment being received at the time" (Donnelly et al., 1985, p. 540). Others attribute alternative medicine successes to the placebo effect. However, increased understanding of the placebo effect is transforming its status from an 
unspecific effect irrelevant to clinical practice to a specific effect that stimulates the selfhealing process and produces improved health. Thus, some researchers consider this criticism of alternative medicine irrelevant (Lynöe, 1990).

Although some alternative therapies may be given to demonstrating effectiveness through controlled, double blind trials (Kleijjnen, Knipschild, \& Riet, 1991), other therapies such as hypnosis and guided imagery are generally not suitable for empirical testing. A primary problem is that many alternative medicines are based on a "world view" that is distinctly different from the conventional scientific paradigm. Therapies that are based in a particular paradigm should be evaluated in terms of that paradigm.

Reductionist evaluative approaches [such as randomized controlled trials and cost-benefit analyses] may well favour, by their very nature, a system of medicine that is itself reductionist [such as conventional medicine] in terms of its scientific and experimental history and its emphasis on organically identifiable disease symptoms. (Patel, 1987a, p. 171)

Methodological problems in the evaluation of alternative medicine will be further explored in the method section of this paper.

\section{Menopause}

Because this study investigates the utilization of alternative medicine by examining the experience of women who use naturopathy for menopausal health care, it is helpful to understand the context that surrounds current thinking about menopause. Health educators, physicians, nurses, alternative practitioners, psychologists, and women themselves have all contributed to the existing body of knowledge about menopause.

Menopause is a natural developmental transition that every woman who lives into her middle age will experience. The biological phenomenon most often characterized as 
menopausal is decreased ovarian estrogen production (Notelovitz, 1987). Low estrogen levels lead to estrogen-dependent symptoms of menopause such as vasomotor instability (hot flashes) and urogenital changes. Though the majority of medical studies link continuing post-menopausal estrogen decline to increased risk for osteoporosis and cardiovascular disease, some researchers feel that the the role of estrogen decline is not clearly associated with these chronic diseases (MacPherson, 1985; Matthews, 1992). Studies concerned with the role of hormones in the aging process have overshadowed the importance of other factors that contribute to disease such as improper diet and lack of exercise (National Women's Health Network, 1989). In recent years, researchers have sought to understand menopause not as a disease but as a normal developmental process (Voda, 1992). This understanding has encouraged the promotion of positive self-care practices that maintain good health throughout the aging process. These practices may include a healthful diet, exercise, proper adherence to a hormone replacement regimen, or participation in women's discussion groups.

Middle-aged women's demand for information about health care options may be one reason for an increase in the publication of popular books about menopause such as Menopause without Medicine (Ojeda, 1992) and Menopause, Naturally (Greenwood, 1984). These books are designed not only to inform women about what to expect during menopause and how to care for themselves, but also to dispel the crippling myths of menopause, both social and biological, that persist to this day. These books, even those which promote long-term estrogen therapy for most women (Sheehy, 1992), demonstrate that understanding of menopause has progressed well beyond Wilson's 1966 Feminine Forever which suggests that unless menopause is "prevented" by aggressive hormone replacement therapy, women are "condemned to witness the death of their own womanhood" (p. 15). 
Few still argue, as did Wilson, that menopause should be prevented, yet many medical physicians continue to feel that, like diabetes, menopause is a deficiency disease, and should be treated as such (Notelovitz, 1987). Some researchers (Martin, 1988; McCrea, 1983) maintain that the mainstream medical community continues to view women's bodies and biological processes as intrinsically defective (as compared to the male norm) and in need of treatment.

Knowledge generated from menopause research arises from three perspectives: biomedical, sociocultural, and Women's Health Movement perspectives (Cooksey, Imle, \& Smith, 1991; Dickson, 1990b). Biomedical studies generally view menopause as a deficiency disease: ovarian "failure" leads to a "deficiency" in estrogen (McCrea, 1983). A majority of medical research is concerned with the risk-benefit equation of hormone replacement therapy. The sociocultural view analyzes the menopausal transition with respect to the psychological, social, and cultural context of women's lives and deemphasises hormonal and other physiological changes that occur during menopause. The Women's Health Movement perspective seeks to understand the normalcy of physiological, psychological, and social events that occur during the middle years of women's lives.

\section{The Biomedical Perspective of Menopause}

The biomedical perspective of menopause is concerned with changes that occur in hormonal levels during the perimenopausal period and with postmenopausal implications of decreased estrogen production. Both short-term perimenopausal symptoms (such as hot flashes) and long-term postmenopausal health risks (such as osteoporosis and cardiovascular disease) have been linked to declining estrogen production by the ovaries. 
Vasomotor symptoms, urogenital changes, and osteoporosis have been approved by the FDA as reasons for prescribing estrogen (National Women's Health Network, 1989).

Lichtman (1991) provides a review of the literature concerning perimenopausal hormone replacement therapy. Estrogen replacement therapy (ERT) use by menopausal women peaked during the 1970's. Later in that decade, an association between noncontraceptive estrogen use and increased risk for endometrial cancer became evident. ERT use dropped significantly, but investigators soon found that adding a progestin to the therapy, thereby simulating the phases of the normal menstrual cycle to ensure that the uterine lining is shed periodically, provided a protective effect against the risk of endometrial cancer. Hormone replacement therapy use (in the form of estrogen and progestin, or HRT) again rose to unprecedented levels. While the medical community now holds that women with intact uteri should generally not receive estrogen unopposed by a progestin, it also recognizes that estrogen-progestin regimens have not been as extensively studied as estrogen-only regimens.

A primary preventive use of HRT is osteoporosis risk reduction. Numerous studies have shown that estrogen decreases the rate of post-menopausal bone demineralization. The 1984 National Institutes of Health Consensus Conference on Osteoporosis recommended estrogen as prevention against osteoporosis in postmenopausal women (Lichtman, 1991). Prince et al. (1991) compared exercise, calcium supplementation, and HRT for the prevention of osteoporosis. They found that while both exercise plus HRT and exercise plus calcium supplementation reduced bone loss in women considered to be at risk of osteoporotic fracture, the exercise-HRT regimen, though producing more side effects such as withdrawal bleeding (continued menstruation) and breast tenderness, was more effective in increasing bone mass than the exercise-calcium regimen. 
Estrogen replacement therapy has also been shown to be beneficial in reducing the risk of cardiovascular disease. Estrogen decreases low-density lipoprotein levels and elevates high-density lipoprotein levels (Stampfer \& Colditz, 1991). Further investigation of the role that progesterone plays in affecting risk of cardiovascular disease will help researchers to understand the effect of HRT on lipid profiles (Semla \& Parent, 1990).

Hormone replacement therapy is prescribed for the alleviation of perimenopausal symptoms such as vasomotor instability and urogenital changes. Some studies have shown that HRT improves psychological symptoms (such as depression) believed to be due to menopause (Ditkoff, Crary, Cristo, \& Lobo, 1991), but researchers agree that HRT will not alleviate preexisting affective disorders (Lichtman, 1991).

Studies that suggest a link between estrogen and breast cancer have renewed the controversy over hormone replacement therapy. Estrogens promote breast cancer in experimental animals, and exposure to ovarian hormones may increase breast cancer risk in humans (Colditz, Stampfer, Willett, Hennekens, \& Speizer, 1990). One meta-analysis (Sillero-Arenas, Delgado-Rodriguez, Rodigues-Canteras, Bueno-Cavanillas, \& GalvezVargas, 1992) reports an increased risk of breast cancer in current and recent users of estrogen, especially in women who have experienced natural (nonsurgical) menopause. Henrich's (1992) review of the literature, however, finds that there is no support for an overall increase in risk of breast cancer in women who used postmenopausal estrogens. Another study (Gambrell, Maier, \& Sanders, 1983) maintains that non-contraceptive estrogen use may have a protective effect against breast cancer. An investigation by Cobleigh et al. (1994) proposes that previous research supports clinical trials of ERT in breast cancer survivors. Semla and Parent (1990) suggest that whether or not the breast cancer risk is proven,

since the addition of cyclic progesterone has become the standard of care for women on ERT to prevent endometrial cancer, the potential role of 
progesterones in the development of breast cancer must be addressed. Unfortunately, few studies have even mentioned progesterone use in their populations. (p. 72)

The majority of biomedical studies conclude that, for most women, the benefits of hormone replacement therapy outweigh the risks. For some women, however, hormone replacement therapy is not an option. Contraindications for HRT include previous history of breast cancer, genetic history of breast cancer, current breast cancer, current endometrial cancer, acute liver disease, acute thrombophlebitis or thromboembolic disorder, and undiagnosed vaginal bleeding. There are numerous relative contraindications for $\mathrm{HRT}$ as well. In addition, for some women, the side effects of hormone replacement therapy (erratic bleeding and spotting, worsening headaches, breast tenderness) are more severe than the short term symptoms of menopause that hormone replacement therapy might relieve (Miller, 1992).

What does the medical community recommend to relieve symptoms and decrease health risks for women who cannot or prefer not to undergo hormone replacement therapy? Pharmaceutical alternatives to estrogen include steroid and non-steroidal medications (Lindsay, 1989; Miller, 1992), as well as other pharmaceuticals that are specific for various symptoms (Young, Kumar, \& Goldzieher, 1990). Additional osteoporosis prevention recommendations include calcium supplementation (Dawson-Hughes et al., 1990; Lindsay, 1989) and exercise (Birge \& Dalsky, 1989; Gannon, 1988; Zhang, Feldblum, \& Fortney, 1992). Although calcium intake unaccompanied by estrogen does not appear to prevent bone loss in postmenopausal women, it is recommended that all women at risk for osteoporosis maintain a level of calcium intake which assures that calcium deficiency is not contributing to bone loss (Lindsay, 1989). Exercise has been shown to increase bone density even when initiated late in life and without ERT (Birge \& Dalsky, 1989). Exercise is also recommended for insomnia (Miller, 1992) and for the prevention and relief of 
problems such as cardiovascular disease, obesity, muscle weakness, osteoporosis, and depression (Shangold, 1990). Relaxation techniques (Germaine \& Freedman, 1984), exercise (Hammar, Berg, \& Lindgren, 1990), avoidance of caffeine, and layered clothing (Miller, 1992) may reduce the frequency of hot flashes. For minimizing urogenital changes a common recommendation is continued sexual activity and Kegel exercises (Beard, 1992).

Lifestyle factors such as diet and exercise, and preventive measures such as cancer and cholesterol screenings are important for the health of aging women. Long term studies comparing HRT with other preventive measures such as adequate calcium intake beginning in childhood, avoidance of tobacco and excessive alcohol, and consistent weight bearing exercise are required to increase researchers' understanding of the affect that these lifetime risk-reduction behaviors have on the health of older women (Lichtman, 1991).

What are the attitudes and experiences of women who seek conventional medical treatment? Biomedical studies about women's experience of menopause investigate the characteristics of women who do or do not use HRT, attitudes of women about HRT, and how women make decisions about HRT.

Egeland, Matthews, Kuller, and Kelsey (1988) found several variables that may predict hormone use including surgical status (hysterectomy and/or oophorectomy), body mass index, race, age, alcohol consumption, and education. Ferguson, Hoegh, and Johnson (1989) assessed factors such as knowledge and attitudes that might influence a woman's decision to use ERT and found that predictors of ERT use include perceiving natural approaches to menopause as less preferable, knowing that estrogen can reduce risk of osteoporosis, viewing menopause as a medical condition, being under the care of a gynecologist, and "recognizing that women who have hot flashes should be taking ERT" (p. 136). 
Schmitt et al. (1991) analyzed information use and judgement making patterns among HRT users. Hormone use was related as much to attitudes about menopause as it was to actual symptoms and knowledge of risk factors. Women's "willingness to take HRT across all cases was related to attitudes about, and knowledge of, menstruation, perceived stress, mother's experience with menstrual problems, severity of symptoms, and use of vitamins" (p. P92). "A major determinant of most women's decisions is their current comfort level (i.e., presence or absence of hot flashes)....Most of the women...were not particularly concerned about the cancer risk involved with ERT" (p. P99). A frequently cited concern of women about HRT is withdrawal bleeding, seen as a notable disadvantage (Draper \& Roland, 1990; Ferguson, 1989).

Logothetis (1991) explored the relationship of perceived benefits and barriers (a key construct of the Health Belief Model) associated with HRT, and philosophical orientation to menopause (a continuum ranging from disease orientation to developmental orientation) in women of 40 to 60 years of age who had intact ovaries. Although the relationship of perceived benefits to perceived barriers accounted for the most variability of decisions about HRT, philosophical orientation toward menopause was the next most significant variable. "The degree to which a woman considers menopause as a disease to be medically managed can be an additional factor for explaining how likely she is to use ERT' (p. 466).

A significant finding that has emerged from research is that women who use hormone replacement therapy are often healthier to begin with (Hemminki, Malin, \& Topo, 1993). For example, hormone users are less obese and have lower blood pressure than nonusers (Matthews, 1992). Typically, they are educated whites (Egeland et al., 1988), a group which generally exhibits fewer risk factors for morbidity and mortality than the overall population. "Usually estrogen users will be healthier than the general population, in part by virtue of their connection with the medical care system" (Stampfer et al., 1991, p. 
53). Thus, women studied with regard to health outcomes of HRT are self-selected and have characteristics which predict better health, including decreased risk for cardiovascular disease.

Biomedical studies have made significant contributions to knowledge about menopause. Biomedical research continues to investigate aspects of menopause including short-term hormone-dependent symptoms, long-term health risks associated with decreased estrogen production, benefits and risks associated with hormone replacement therapy, alternatives to hormone replacement therapy, and characteristics and attitudes of women who use hormone replacement therapy. Research investigating the latter category suggests that sociocultural variables are significant with respect to women's use of HRT.

\section{The Sociocultural Perspective of Menopause}

The sociocultural perspective views the symptoms associated with menopause not as an outcome of hormonal changes, but as a result of social and cultural circumstances of women at midlife. Numerous symptoms have been attributed to menopause, including affective disorders such as tiredness, irritability, and depression. Lists of symptoms associated with menopause may exceed 30 items (Kaufert \& Syrotuik, 1981).

The experience of women has been used to explore the psychosocial context of symptoms and symptom reporting. In a study of 36 women, Hunter (1990) found that past depression as well as cognitive and social factors accounted for half of the variance in depressed mood reported during menopause. Hunter concluded that

while biological explanations cannot be ruled out on the basis of current knowledge, psychological and social factors (previous depression, negative beliefs, unemployment, and socioeconomic status) appear to be adequate to explain a reasonable proportion of the variation in mood reported by menopausal women. (p. 355) 
Engel (1987) measured perceived health status, recent life events, and sex role orientation at menopause and found that if women had recently experienced significant life changes, their perceived health status was lower. Their perceived health status was also lower if their attitudes toward women's roles were less traditional.

McKinlay, McKinlay, and Brambilla (1987a) measured health status, prior health status, and utilization behavior and found that menopause is not a cause of poorer health status, nor does it cause an increase in utilization behavior. However, surgical status (hysterectomy or oophorectomy) does affect perceived health status and utilization behavior, as does prior health status. One of the study's findings regarding utilization behavior is that a large proportion of women seeking medical assistance at menopause have undergone hysterectomy or oophorectomy. Women who have had such surgery tend to have a higher rate of preexisting chronic conditions than women who have had natural menopause.

McKinlay et al. (1987b) also measured depressive symptoms in middle-aged women and found that, with the exception of women who had recently experienced a hysterectomy or oophorectomy, depression was not associated with or triggered by endocrine changes but rather was associated with "multiple causes of worry and multiple roles among currently married women (including paid work, adolescent children, ailing husbands, and aging parents or parents-in-law)" (p. 345). This study found that the rate of depression was twice as high in women who recently experienced hysterectomy or oophorectomy as in the other menstrual status groups. Thus, studies that include menopause as an explanatory variable should separate surgical from natural menopause subjects.

A study by Køster (1991) supports the theory that attitudes prior to the onset of menopause determine the nature of symptoms at menopause. Questionnaires given to 336 
51-year-old women were analyzed to find that women's conception of health in earlier life, former sexual habits, and anticipation of complications (factors unrelated to hormonal changes) were associated with the quality of both health and sexuality during this period.

Several studies suggest that menopause is not a major concern in the lives of many women. Notman (1979) stated that

emerging data indicate that menopause does not appear to be the central event for women's middle age or to be responsible for most of the symptoms. Midlife stresses are the result of a combination of personal, family, social, and biological variables, with postmenopausal development an important phase. (p. 1270)

Notman's conclusion is supported by Leiblum and Swartzman (1986) who measured 120 premenopausal, 39 perimenopausal, 64 postmenopausal and 21 hysterectomized women's views of menopause, attitudes toward HRT, and perceptions of sexuality. Although the women generally regarded menopause as a medical event, it was not a major event, and they preferred natural treatment options over hormone replacement therapy. Life changes were more influential to them than hormonal fluctuations, and they "rejected the notion that sexuality is seriously compromised subsequent to the menopause" (p. 54). This study, however, did not specify whether women in the sample were using hormone replacement therapy. Use of HRT for the alleviation of symptoms could explain attitudes that minimize the significance of menopause. The use of hormone replacement therapy by menopausal women could also explain why "younger women anticipating menopause were more concerned than women who were actually menopausal" (Notman, 1979, p. 1270).

Matthews et al. (1990) investigated the influence of natural menopause on psychological characteristics and found that

natural menopause led to few detectable changes in women's psychological characteristics. Natural menopause did not adversely affect Type A behavior, anxiety, anger, total symptoms, depression, public selfconsciousness, perceived stress, or job dissatisfaction scores. It did not 
adversely affect reports of recent symptoms of body worry, excitability, aches in neck and skull, depression, nervousness, and difficulty sleeping. The only reliable effects of natural menopause were that for women who became postmenopausal and did not use hormone replacement therapy, level of private self-consciousness declined at the same time they reported more often experiencing hot flashes. (p. 349)

One area of menopause research which supports the influence of sociocultural factors on women's experience of menopause derives from investigations of women of non-Western cultural backgrounds. These studies examine menopausal experience in countries where attitudes toward women and aging are vastly different than attitudes found in Western industrialized countries. George (1988) found that among a group of Sikh women living in a Canadian city, "traditional psychological and psychosomatic symptoms ascribed to menopause in the literature were notably absent" (p. 109). "The women in this study reported menopause to be a natural phase in the developmental cycle of life and the culture proscription that anything natural demands no special attention prevailed, even though it could bring accompanying discomforts, aches or pains" (p. 115).

Martin, Block, Sanchez, Arnaud, and Beyene (1993) studied the characteristics of menopause among Mayan women who did not have menopausal symptoms and concluded that

the same endocrine event, the menopausal transition, can result in markedly different symptoms in differing patient populations and that the ultimate consequences of estrogen deprivation on bone can result in different clinical manifestations, which is mediated by other as yet undetermined factors." (p. 1843)

Flint (1975) examined the perception and experience of women in several nonWestern cultures and found there to be fewer menopausal problems than in Western cultures. She suggested that this difference could be attributed to the roles that are expected of women. Whereas during their reproductive years women in some societies are veiled and secluded and considered unclean while menstruating, at menopause they are allowed to 
participate in society with elevated social position. Thus, a menopausal woman was rewarded for having achieved her menopause. In Western industrialized countries, on the other hand, "with its emphasis on youth and glamour, the loss of youth signified by the menopause presents difficulties for many women....In our culture, there is no reward for attaining menopause" (p. 163).

Research has shown that many negative symptoms attributed to menopause such as depression and anxiety are determined by factors such as previous depression and social and personal stresses. The sociocultural perspective of menopause is supported by studies in which changes significant to women at midlife are more closely related to social and cultural circumstances than to midlife hormonal changes. Investigating this concept further, many feminist writers examine the social implications of menopause as it relates to ageism and sexism in our society.

\section{Women's Health Movement Perspective of Menopause}

The majority of studies concerned with women at midlife, both from the biomedical and sociocultural perspectives, examine only the negative aspects of menopause. Positive aspects of menopause are explored in popular books such as Ourselves, Growing Older (Doress \& Siegal, 1987), Menopausal Years: The Wise Woman Way (Weed, 1992), and Menopause, Naturally (Greenwood, 1984).

After the menopause there are no more menstrual cramps, bleeding problems, or tampons and pads. There are no more aching pelvic discomforts with and after ovulation, no more tender breasts before a period, and no more mood swings with premenstrual tension. There are no more problems with endometriosis, fibroid tumors, birth control devices, or unwanted pregnancy. Migraine headaches tend to disappear. Not all women experience all these aggravations, but most have had some of them. Freedom from these difficulties is an aspect of the menopause to be enjoyed. (Greenwood, 1984, p. 17) 
In further exploring menopause, feminist studies have found that it represents not just the absence of menstrual difficulties, but also a time for personal growth.

Some women experience this period as being "restored to themselves" and to their own development....The possibilities for expansion do exist. The potential for greater autonomy, changes in relationships, and the development of occupational skills, interpersonal contacts, and an expanded self-image may receive a major impetus after childbearing is over. (Notman, 1979, p. 1273)

Women...want to experience the menopause. They want to bring closure to menstrual life. They are eager to transit the climacteric into the nonreproductive years. (Voda, 1992, p. 931)

Not only are positive aspects of menopause rarely addressed in the biomedical and sociocultural literature, but the emphasis of research on the negative experience of midlife women may contribute to negative stereotyping of aging women.

That the majority of the educated public, which also produces and consumes the products of mass media, learns so little about women's development and within such a narrow theoretical range is of consequence, especially to women, who must build their prospectus of adult life in large part from this knowledge base. (Gergen, 1990, p. 474)

Menopause research that dwells heavily upon negative aspects of menopause contributes to a cycle of negativity and precludes research that might illuminate benefits of menopausal experience. Matthews (1992) suggests that "women's expectations about aspects of the menopause affect their psychological experience during the menopause.... Expecting negative menopausal symptoms may lead to a self-fulfilling prophesy" (p. 5). Because research has a significant impact on the manner in which menopause is presented in professional and lay literature, Mansfield, Jorgensen, and Yu (1989) encourage researchers to

take care to eliminate the possibility of bias created by the social stigma associated with the menopause....Researchers themselves must be careful not to introduce negative stereotypes to their study design. In early studies (and sometimes in current ones), menopausal symptom checklists contained 
only negative items because these reflected expectations of the investigators. It is suggested that equal numbers of positive and negative items appear and that a neutral-sounding term (e.g., "experiences" or "events") rather than the negative-sounding term "symptoms" be used. (p. 48)

In keeping with the spirit of this suggestion, this study will henceforth refer to menopause changes as signs.

This critical approach to menopause research is supported by feminist theory. Feminist theory is used by researchers to discover women's experience of menopause independent of biomedical and sociocultural assumptions (Dickson, 1990a). The knowledge generated from such research provides information that is directly useful to women during their menopausal years. Such information is made available through the publication of materials by organizations such as the Women's Health Movement (WHM).

The WHM, which is promoted by both feminists and nonfeminists (Voda, 1992), is distinguished from the broader Women's Movement by its emphasis on health and body issues. The WHM stresses that women take an active role in their health care rather than passively accept the services of an expert (MacPherson, 1991). Books such as The New Our Bodies, Ourselves (The Boston Women's Health Book Collective, 1984), and Ourselves, Growing Older (Doress \& Siegal, 1987), reflect the WHM commitment to disseminate information to women that increases the understanding of their own bodies and empowers them to make appropriate, informed decisions about medical care. The WHM perspective of menopause, like the sociocultural perspective, de-emphasizes the debate over hormone replacement therapy.

Whether or not risks associated with hormone use outweigh their benefits is not an issue that should be deliberated. Menopause is a normal process, and as such, there is no risk to health for most women who experience menopause naturally. The issue that should be addressed is the Wilsonian myth of menopause as a disease, which has resulted in widespread treatment of women. (Voda, 1992, p. 930) 
Bell (1987) outlines how, through biological, psychological, and environmental models developed in the 1930's and 40's, menopause has been "medicalized," or transformed from a normal physiological event to a pathological and abnormal condition. McCrea (1983) provides a historical social context out of which attitudes toward menopause evolved that allowed for the widespread prescription of hormones.

The National Women's Health Network Position Paper on HRT (1989) suggests that normal menopause is not a deficiency disease, and menopause does not automatically require treatment. The National Women's Health Network is "critical of the routine prescribing of hormones for healthy women because of the known risks associated with the drugs used and the lack of complete data on risks and benefits (National Women's Health Network, 1989, p. 2).

From the Women's Health Movement perspective, pharmaceutical companies have to a large extent dominated research on menopause through their funding of particular scientists and scientific conferences....This pharmaceutical funding has contributed to a biased definition of menopause and an overemphasis on HRT as the treatment of choice. Vigorous promotion of hormones which generate high profits overshadow reports of research on natural, safer, healthier and less expensive ways of dealing with menopausal changes and of ways to prevent osteoporosis. (MacPherson, 1991, p. 203)

Alternatives strongly supported by the Network Position Paper include nutrition, exercise, and calcium supplementation. However, the National Women's Health Network does not completely reject the use of HRT: "Women who have had their ovaries surgically removed, who experience extreme menopausal discomfort, or who are at high risk for osteoporosis, may find HRT useful" (MacPherson, 1991, p. 203).

An outcome common to several feminist, sociocultural, and biomedical studies that focus on women's experience of menopause is that women want more information about what to expect and what is normal during menopause than is typically provided by their health care provider (Berkun, 1986; Draper, 1990; Quinn, 1990; Schmitt et al., 1991). 
Women feel 'frustration over their physicians' discomfort with the subject of menopause and concern with the quality of care they received" (Mansfield, 1992, p. 79). One study (Holmes et al., 1987) compared physician estimates of perimenopausal women's values with women's directly assessed values related to possible outcomes of hormone replacement therapy. It was found that physicians' and women's assessments were not in agreement. For example, physicians rated relief of signs as more important than fracture prevention, whereas women rated fracture prevention as more important than relief of menopause signs. "These results emphasize the need to assess patients' utilities directly, particularly when utilities for the outcome of a particular therapy may influence the choice of a therapeutic regimen" (p. 178).

One issue frequently raised in feminist as well as biomedical and sociocultural literature is the lack of normative data about menopause (Mansfield, 1992). Research has traditionally studied populations of women who reported signs at the time of menopause to their physicians, and results were taken to be true for the entire population. Thus, selfselection of symptomatic women was guiding much of what was known about menopause until recently. "The contention that high rates of psychological symptoms are only found in clinic populations...has led to the use of general population samples in menopausal research, where vasomotor and somatic difficulties are found to be not uncommon, but lower rates of psychological problems are generally identified” (Ussher, 1992, p. 133).

Mansfield et al. (1989) discuss other methodological issues, including problems arising from the "biology versus culture" (p. 47) approach to analysis. The feminist view, according to Dickson (1990a), departs from both the biomedical and the sociocultural views in its criticism of the methods used to understand menopause. The majority of both the biomedical and the sociocultural studies are

based on an intellectual tradition in which the linear, causal model of research dominates. Each of the views presents a fragmentary and 
reductionistic view of women and menopause by focusing on variableseither biologic or sociocultural-to explain the phenomenon of menopause. (p. 18)

Many researchers advocate an interactional approach that brings together biological and cultural influences (Kaufert \& Gilbert, 1986; Logothetis, 1991; Mansfield et al., 1989). "Strategies, such as the use of open-ended semistructured or unstructured interviews, may be required to uncover the meaning of menopause among midlife women" (Engel, 1987, p. 356). Methodological issues in menopause research will be explored further in the method section of this paper.

\section{Menopause and Naturopathic Medicine}

The practice of naturopathic medicine is based upon several principles of healing that include the support of the body's own healing abilities, the use of natural and nontoxic therapies, and the education of the patient in the laws of healthy living. The key to success of naturopathic therapy is a high level of involvement of patients in their own healing process (Murray \& Pizzorno, 1990).

Naturopathic medicine is 'vitalistic' in its approach, i.e. life is viewed as more than just the sum of biochemical processes and the body is believed to have an innate intelligence that is always striving for health....Symptoms, then, are part of a constructive phenomenon that is the best 'choice' the organism can make, given the circumstances. In this construct, the role of the physician is to aid the body in its efforts, not to take over the functions of the body. (Murray \& Pizzorno, 1990, p. 6)

Naturopathic medicine (NM) utilizes techniques such as clinical nutrition, botanical medicine, physical medicine (including gentle manipulation, specific application of heat and cold, ultrasound, massage, and exercise therapy), hydrotherapy, homeopathic remedies, Oriental medicine, and counseling. It does not use invasive procedures other than minor 
surgery. NM shares many techniques with conventional medicine including diagnostic procedures such as x-rays, physical examinations, laboratory testing, gynecologic exams, and metabolic analysis. But the naturopathic view of health and healing differs from the conventional view:

Underlying naturopathy is the doctrine of vitalism, according to which living organisms are subject to a 'vital force' which acts independently of physical forces. This force...promotes harmony and homeostasis, even in illness, which is an adaptive response to unnatural conditions. The vitalist assumption...is contrary to the depiction by Western, scientific medicine of the body as a helpless machine subject to the potentially antagonistic, random forces of nature. (McKee, 1988, p. 778)

Naturopathic physicians prepare for licensure and practice by completing a fouryear graduate program focusing on standard medical sciences (including cardiology, gynecology, neurology, pathology, pediatrics, biochemistry, immunology, obstetrics, pharmacology, and minor surgery), history and philosophy of naturopathic medicine, and clinical training in diagnosis and naturopathic therapeutics. Additional course work and clinical training is required for specialties in natural childbirth and homeopathy (National College of Naturopathic Medicine-a).

Many recommendations made by naturopathic physicians for menopausal health converge with recommendations suggested in the medical literature for women who may not or prefer not to undergo hormone replacement therapy. These recommendations include calcium supplementation, proper diet, and exercise for prevention of osteoporosis and cardiovascular disease; and Kegel exercises for urogenital changes (Hudson, 1992).

Naturopathic management of menopause includes an evaluation of past medical history and current medical problems. Appropriate tests are performed to determine the optimal way to prevent and manage problems due to low estrogen levels. Naturopathic physicians believe that most menopause signs, including hot flashes and osteoporosis, can be prevented or treated with naturopathic approaches such as dietary recommendations, 
specific plant extracts (botanicals) that have the ability to promote optimum hormonal balance, homeopathy, hydrotherapy (treatment with water to improve circulation, reduce blood pressure, and improve sleep and digestion), nutritional supplements, physical medicine and exercise, and counseling (National College of Naturopathic Medicine-b). A study was conducted that investigates the efficacy of botanical preparations containing phytoestrogens (Glycyrrhiza glabra, Arctium lappa, Angelica sinensis, Leonarus cardiaca, Dioscorea villosa) on the signs of menopause. Results showed improvement for several signs common to the menopausal transition (Hudson et al., 1993). Naturopathic physicians (N.D.s)

also treat many women who are already taking ERT who are still not feeling well. The addition of naturopathic therapies can make these women more comfortable and often leads to the discontinuation of ERT....There are medical situations where N.D.'s recommend a complementary approach to menopause management. In cases where ovaries have been removed or damaged... [at an early age], N.D.'s currently would not hesitate to prescribe ERT. In those cases, N.D.'s use naturopathic therapies to reduce the risks of estrogen therapy and to further enhance overall health while reducing the risks of osteoporosis and heart disease. (National College of Naturopathic Medicine-b)

Summary of Literature Review

The preceding review of the literature regarding alternative medicine and menopause is not meant to be exhaustive, but rather to present examples of research and theory that provide a context for the present study. This inquiry will return to the literature when data collection and analysis give rise to issues which require textual interpretation. 


\section{Summary of Current Trends in Research and Theory about Alternative Medicine}

Alternative health care is increasing in popularity in the United States, but the literature is limited with regard to research concerned with alternative medicine. Of the research that has been conducted, areas of study include utilization of alternative medicine and evaluation of alternative therapies. Theories about motivating factors associated with patients' utilization of alternative medicine include dissatisfaction with conventional medicine; seeking a solution to a health problem; beliefs about health, illness, and treatment; and psychological needs of the patient.

The federal government has created an office for the purpose of evaluating alternative medicine. Continued research investigating the efficacy of alternative therapies can be expected. Evaluating alternative health care is problematic in some cases because alternative health care systems arise out of a paradigm that differs from that which conventional medicine is based upon.

\section{Summary of Current Trends in Research and Theory about Menopause}

Three perspectives of menopause are presented in the literature: (a) the biomedical perspective, which focuses on the risk-benefit equation of hormone replacement therapy; (b) the sociocultural perspective, which focuses on the social and cultural influences upon changes that occur at midlife; and (c) the Women's Health Movement perspective, which focuses on the normalcy of menopause and promotes self-care practices. These three perspectives are not exclusive. Research areas that are viewed as important from all perspectives include utilization behavior, attitudes about menopause, and experience of menopause. 


\section{Statement of Problem}

Increasingly, the public is demanding information about choices in health care, including choices in alternative medicine. An important role of the health educator is to present information to individuals about health care options. In instances where women are seeking assistance in making decisions about menopausal health care, the health educator must understand options that are available to women who seek treatment, including options in alternative medicine. However, because menopause research relies heavily upon the characteristics of women who attend conventional medical clinics, health educators lack data that reflect the experience of women who choose alternative approaches to menopausal health care. Studies find that women do not feel they get adequate information about menopause from their health care provider.

Many women pass through menopause without incident, but for those who do have difficulties, the naturopathic approach to menopause, which favors a healthful lifestyle and natural remedies, is one treatment option. This study was designed to increase understanding of the naturopathic approach to menopause from the perspective of women who have chosen naturopathic treatment. Three areas of inquiry were explored:

(a) Why do women select naturopathic health care during the menopausal transition?

(b) Do women who use naturopathic treatment for menopausal health care share similar experiences of menopause?

(c) Are women satisfied with the naturopathic treatment they receive for menopausal health care? 
To investigate the problem, a research method was chosen that effectively explored the experiences of women with respect to these three areas of inquiry. Following a review of methodological issues in both alternative medicine and menopause research, the research design of this study will be described. 


\title{
CHAPTER III
}

\section{METHOD}

\section{Evaluation of Alternative Medicine}

\begin{abstract}
Alternative medicine has not been extensively researched, yet its acceptance by the American public continues to increase. The Office for the Study of Unconventional Medical Practices advocates that

alternative medical researchers should be required to present their data using the same strict scientific methodology performed by their peers who practice [conventional] medicine. This should include double-blinded randomized trials, traditionally trained scientific review committees to evaluate data, and meta-analyses. (Mahaney, 1992, p. 1069)
\end{abstract}

But this analytical, reductionistic approach may not be the best criteria by which to evaluate all kinds of alternative medicine. For example, although several rigorous, double-blind, controlled studies of homeopathy are contained in the literature, comparing it with conventional therapies is problematic.

Homeopathy...does not lend itself to controlled, clinical study because remedies are individualized for each to match the peculiar symptoms of the patient, rather than standardized to treat a disease common to many. Since the course of illness differs among individuals, with each set of new symptoms requiring a new remedy, the effects of homeopathic remedies cannot be easily predicted, repeated or compared. (McKee, 1988, p. 782) 
This is true for other types of alternative medicine, and it is also true of many conventional therapies. It is increasingly clear that the outcome of a treatment or a disease is the result of complex interrelationships among variables, many of which are difficult to identify.

Patel (1987a) and Calabrese (1992) advocate outcomes studies for the evaluation of alternative medicine. Outcomes studies focus on whether or not patients' quality of life has improved after undergoing a particular therapy. "The patients' own feelings should be considered as one of the most important indexes for evaluating AM" (Jingfeng, 1987, p. $663)$.

Some researchers suggest that a new paradigm methodology be used to study health issues which lie outside of the conventional medical paradigm. This new paradigm research moves toward complex, heterarchical, holographic, indeterminate, mutually causal, morphogenic, perspective methods; and away from simple, hierarchical, mechanical, determinate, linearly causal, assembled, objective methods (Lincoln \& Guba, 1985).

It is predominantly in the sphere of nonspecific undifferentiated illness, i.e. homeostatic imbalance, that the greatest potential of the complementary therapeutic systems lies, and new paradigms of research are needed for adequate assessment of these. (Tonkin, 1987, p. 362)

Qualitative methodology has been used to investigate patients' experience of alternative medicine. Montbriand (1993) used ethnography, a qualitative methodology, to examine the beliefs and practices of Canadian cancer patients who use alternative therapies. Findings from this study indicated that patients experienced difficulty in finding reliable sources of information about alternative choices in medicine. The study also suggests that "patients clearly were active, not passive, participants in making healthcare choices" (p. 1199). Montbriand and Laing (1991) used a phenomenological perspective to illuminate "the patients' view of control, a view not easily accessed with quantitative methodology" 
(p. 331). Murray and Shepherd (1993) conducted 20 extended interviews with users of alternative medicine in Great Britain to explore patients' motivations for trying alternative medicine, patients' selection of alternative treatments, what conditions alternative treatments were selected for, and the results of alternative treatment. This study found that "questions of efficacy and scientific research were regarded as secondary to the avoidance of unknown long-term dangers from modern medical interventions....The therapist's time and attention were the most highly valued aspect [sic] of alternative practice" (p. 986).

\section{Evaluation of Menopause Experience}

Research methodology can define or shape knowledge that emerges from the investigative process:

In looking at the knowledge of menopause through the biomedical and sociocultural metalanguage, the links between the sets of assumptions about science, women and menopause can be seen to create distinct and separate images of menopause, all of which leave out the holistic experiences of women during the menopausal transition. Creating a conceptual view of knowledge from the outcomes of research, then, continues the circle of knowledge, learning more about less and less while new knowledge of a complex phenomenon such as menopause remains elusive. (Dickson, 1990b, p. 171)

Some of the problems associated with menopause research have already been noted in the literature review. These include the finding that women who take HRT are healthier to begin with, the need to separate surgical and nonsurgical samples, the lack of normative data, and the lack of knowledge of the lived experience of women with regard to menopause.

The most central flaw in previous menopause research is that it fragments a complex biosocial and biopsychological phenomenon, focusing on one or 
two aspects as though they were representative of the whole or uninfluenced by other factors. The presumption that the menopause can be studied through one or several of its aspects to the exclusion of others has hindered the development of a general understanding of the scope and impact of the menopause experience. (Goodman, 1982, p. 273)

In response to these criticisms, research that is concerned with women's experience of menopause has, in recent years, moved away from strict, quantitative designs that narrow the conceptual framework of menopause. Increasingly, researchers are utilizing qualitative methods to broaden understanding of the normalcy of the menopausal experience. Randomized, double-blind controlled trials are an appropriate method of studying, for example, treatments designed to prevent osteoporosis and cardiovascular disease in older women, and prospective studies are essential to understanding the epidemiology of cancers that appear to be hormone dependent. To gain relevant information about women's lived experience of menopause, however, qualitative methods can provide information that would otherwise remain hidden.

Qualitative methods can be used to uncover and understand what lies behind any phenomenon about which little is yet known. It can be used to gain novel and fresh slants on things about which quite a bit is already known. Also, qualitative methods can give the intricate details of phenomena that are difficult to convey with quantitative methods. (Strauss \& Corbin, 1990, p. 19)

Following are several examples of research that utilized qualitative methods for the study of menopausal experience.

Quinn (1991) interviewed a purposive sample of 12 perimenopausal women. Grounded theory, a qualitative methodology used to build theory from data, was used to examine the perspective of the perimenopausal process. Cooksey, Imle, and Smith (1991) "used grounded theory methodology to yield information about menopause as a transition in women's adult development. Transcripts of interviews with 10 recently menopausal women were examined to produce a conceptual model of the transition process" (p. 107). 
The conceptual model that emerged from this analysis consisted of categories of data that described experience common to these women. Dickson (1990a) conducted "free flowing" interviews with 11 women and used textual analysis to understand historical and social contexts. Results contributed to knowledge that is not based on the traditional perspectives of menopause. McKeever (1991) posed two questions: (a) What are the informal explanatory models used by perimenopausal women to explain their menopausal experience? and (b) What are the practices used by perimenopausal women to negotiate the menopausal transition? Through semi-structured interviews and interpretive analysis a descriptive ethnography of natural menopausal experience emerged to reveal "four groups or informal models that depict particular types of menopausal meaning, beliefs and practices” (p. 239). Buck and Gottlieb (1991) interviewed eight Mohawk women who identified four major issues experienced at midlife "related to the concept of time along expected, developmental, personal, and meaningful dimensions" (p. 45).

Using qualitative research methods, these studies were able to build models of menopause based on the perspectives of women experiencing menopause. McKeever suggests than an understanding of these models can help physicians and health educators to recommend health care alternatives that best match the patient's outlook:

When client and physician models compliment one another satisfaction and probable compliance is [sic] more apt to occur than when these belief systems are at odds with one another. It behooves health professionals to begin with the lived experience of women in menopause rather than to operate solely from their own explanatory model. Understanding these meanings and practices inherent in the lived experiences of women in menopause would help nurses, physicians and other health care professionals better negotiate mutually agreeable self-help, medical therapies, and educational programs for these women. (p. 252) 
Research Design

The research questions around which this study was designed are:

(a) Why do women select naturopathic health care during the menopausal transition?

(b) Do women who use naturopathic treatment for menopausal health care share similar experiences of menopause?

(c) Are women satisfied with the naturopathic treatment they receive for menopausal health care?

The literature suggests that menopause gives rise to individualized patterns of physiological and psychological experience, and that individualized treatment is necessary to best meet the needs of middle-aged women. Quantitative strategies such as isolating events, controlling variables, and randomizing subjects would further conceal the unique experience of women who use naturopathic medicine during their menopausal transition. Therefore, to discover the unique experience of a group of women who use naturopathic medicine during their menopausal transition, qualitative strategies were utilized in this study.

In qualitative research, the focus of attention is on the perceptions and experiences of the participants. What individuals say they believe, the feelings they express, and explanations they give are treated as significant realities. In that sense, this is a profoundly relativistic view of the world. The researcher is not seeking the kind of verifiable and absolute "truth" that functions in a cause and effect model of reality. The working assumption is that people make sense out of their experiences and in doing so create their own reality. In qualitative research, understanding both the content and construction of such multiple and contingent realities is regarded as central to answering the question, "what's going on here?" (Locke, Spirduso, \& Silvermen, 1993, p. 99) 
The purpose of this study was to explore the experiences of women with respect to the three research questions. In-depth interviews and grounded theory increased understanding of women's choice of naturopathic health care during the menopausal transition and allowed for the emergence of knowledge about women's experience of menopause.

\section{Selection of Informants}

Eight licensed naturopathic physicians chosen from the Portland, Oregon phone book were invited to assist in recruiting women who used naturopathic medicine for menopause-related health care. N.D.s who specialized in women's health were contacted first. A special effort was made to include male N.D.s. (Of the 16 informants interviewed, 5 were patients of male N.D.s.) Information packets were sent to those N.D.s who expressed interest in the study. N.D.s electing to assist in recruitment of informants contacted, by phone or letter, patients to whom they had provided menopause-related health care. Those women who agreed to have their names released by their naturopathic physician were invited, by letter, to participate in the study (Appendix A).

This method of selecting as sources of data a small number of informants who represent aspects of information or knowledge with regard to the research questions is described as a purposive sampling procedure (Lincoln \& Guba, 1985, p. 199-202). The informants are self-selected and as such, they "have something to say" about their experience. This sampling procedure provided a number of "information-rich" cases (Patton, 1990, p. 169). 


\section{Data Collection}

Upon notice of willingness to participate, respondents were called by phone and an appointment was made. Interviews were held at a place mutually agreeable to the informant and interviewer.

Prior to the interview, informants reviewed and signed the consent form (Appendix B). Interviews commenced with the collection of background information (Appendix C). Because in-depth interviews were conducted in order to "absorb and uncover potentially relevant data” (Strauss \& Corbin, 1990, p. 181), interviews were not tightly structured. However, in order to maintain consistency and to remain within the scope of this inquiry, an interview guide was used (Appendix D).

The interview guide provides topics or subject areas within which the interviewer is free to explore, probe, and ask questions that will elucidate and illuminate that particular subject. Thus the interviewer remains free to build a conversation within a particular subject area, to work questions spontaneously, and to establish a conversational style — but with the focus on a particular subject that has been predetermined. (Patton, 1990, p. 283)

The interview guide initially consisted of seven primary questions about naturopathy utilization and/or menopause. "Probes," or follow-up questions (Patton, 1990, p. 324) were used to elicit additional information that was not forthcoming in response to the primary questions. Related topics not specifically included in the interview guide were explored if respondents volunteered information relevant to the study. As data collection proceeded concurrent with data analysis, the interview guide was modified to reflect and validate the results of analysis (Appendix E). In grounded theory methodology, such modification to the interview guide is an important procedure designed to confirm that emerging concepts remain appropriate representations of data under different sets of conditions. Further, this procedure serves to specify conditions under which the emerging concepts hold (Lincoln \& Guba, 1985, p. 273; Strauss \& Corbin, 1990, p. 191). 
Interview lengths ranged from approximately 20 to 40 minutes. Interviews were transcribed.

\section{Data Analysis}

The grounded theory method of analysis was developed by Glaser and Strauss (1967) as a means for "systematic discovery of the theory from the data of social research" (p. 3). Several texts (Glaser, 1978; Strauss, 1987; Strauss \& Corbin, 1990) are available that describe procedures used to elicit theory from data.

A grounded theory is one that is inductively derived from the study of the phenomenon it represents. That is, it is discovered, developed, and provisionally verified through systematic data collection and analysis of data pertaining to that phenomenon. Therefore, data collection, analysis, and theory stand in reciprocal relationship with each other. One does not begin with a theory, then prove it. Rather, one begins with an area of study and what is relevant to that area is allowed to emerge. (Strauss \& Corbin, 1990, p. 23)

Three phases of research guide the analysis of data and formulation of theory. These phases are data collection, coding, and memoing. Data collection for this study is described above. Coding refers to the detailed examination of raw data leading to the generation of categories of information and concepts. In this study, levels of coding included open coding, axial coding, and selective coding. Open, axial, and selective coding were performed both manually and with the assistance of a computer program (Hesse-Biber, Kinder, Dupuis, \& Tornabene, 1991-1992).

Open coding is "the process of breaking down, examining, comparing, conceptualizing, and categorizing data" (Strauss \& Corbin, 1990, p. 61). Single lines, sentences, or complete thoughts in the texts of interview transcripts are compared, grouped, and assigned a code according to commonalites. Data may be assigned more than one code. Examples of initial codes generated from analysis of transcripts from this study 
include I don't like taking drugs or pills, Conventional medicine didn't work for menopause, Conventional medicine didn't work for a previous health matter, and My personal health outlook. Codes were compared and those that pertained to the same phenomena were "grouped together under a higher order, more abstract concept called a category" (Strauss \& Corbin, 1990, p. 61). For example, the codes I don't like taking drugs or pills and My personal health outlook were initially included in the category named Practicing Natural Health. The codes I don't like taking drugs or pills, Conventional medicine didn't work for menopause, and Conventional medicine didn't work for a previous health matter were initially included within the category named Rejecting the conventional system of health care. Codes may have been grouped under more than one category.

Axial coding consists of intense analysis performed around one category at a time, resulting in cumulative knowledge about relationships between that category and other categories. "Data are put back together in new ways after open coding by making connections between categories" (Strauss \& Corbin, 1990, p. 96). In this study, for example, axial coding revealed that informants who did not practice natural health when they rejected the conventional medical system later did practice natural health after contact with an alternative medical system.

Selective coding refers to "the process of selecting the core category, systematically relating it to other categories, validating those relationships, and filling in categories that need further refinement and development" (Strauss \& Corbin, 1990, p. 116). A core category is "the central phenomenon around which all the other categories are integrated" (Strauss \& Corbin, 1990, p. 116); a core category "accounts for most of the variation in a pattern of behavior" (Strauss, 1987, p. 34). In this study, a core category emerged and was named Exchanging information. Continued analysis illuminated the relationship 
between previously developed categories and the core category. For example, exchanging information is an aspect of practicing natural health, and exchanging information is facilitated by the use of naturopathic medicine. In addition to the formulation of the core category, selective coding allowed for further development and refinement of categories. In this study, the category Practicing natural health was broadened to include Healthy lifestyle, and its name was changed to Practicing natural self-care because this term more accurately conceptualized both current and incoming data as interviewing, coding, and memoing progressed.

Throughout the coding procedure of the grounded theory method of data analysis, theoretical ideas are recorded as memoranda. Memos are the products of analysis and consist of summaries, theoretical questions, or hypotheses. Memos allow the analyst

to make statements of relationship and to validate these statements with the data....Such statements are then checked against each case to determine whether or not they fit. Again, one is looking to see if they fit in a general sense and in most cases, not necessarily in every single case exactly. Continuing modifications and changes can be made in the statements until a general match is made. (Strauss \& Corbin, 1990, p. 138-139)

One memo in this study, for example, proposed that the kind of interaction that occurred between naturopathic physicians and their patients contributes to women's satisfaction with naturopathy as much as does effectiveness of treatment. Continued analysis both validated and contributed to descriptive detail about this concept and its relationship to the emerging grounded theory.

Data collection, coding, and memoing, form a "triad of analytic operation" (Strauss, 1987, p. 18). Initially they are performed in a sequential fashion, but as the phases of analysis become increasingly integrated into theory, coding and memoing continue to raise fresh questions that can only be addressed by the gathering of new data or the examination of previous data. In this study, continued interviewing with new informants and 
modifications to the interview guide were undertaken to illuminate the nature of categories. Eventually new data added little to the development of categories, at which point the categories were considered "saturated." In addition, "testing" was built into each step of the process. Testing is "constantly comparing hypotheses against reality (the data), making modifications, then testing again. Only that which is repeatedly found to stand up against reality will be built into the theory" (Strauss \& Corbin, 1990, p. 187).

In grounded theory, a coding paradigm (Strauss, 1987, p. 27-28) or a paradigm model (Strauss \& Corbin, 1990, p. 99) is used to systematically link categories and subcategories to create "a descriptive narrative about the central phenomenon of the study" (Strauss \& Corbin, 1990, p. 116). The coding paradigm "functions as a reminder to code data for relevance to whatever phenomena are referenced by a given category, for the following: conditions, interaction among the actors, strategies and tactics, [and] consequences" (Strauss, 1987, p. 27-28). The coding paradigm assisted in analysis of the data generated from this study, and use of the coding paradigm at final integration, or "the leap between creating a list of concepts and producing a theory" (Strauss \& Corbin, 1990, p. 117), revealed that the core category, Exchanging information, played a significant role in all aspects of informant's experience of using naturopathy for menopause-related health care. The final step of data analysis occurred when categories were integrated into a narrative layout of the grounded theory (Strauss \& Corbin, 1990, p. 134). The final grounded theory is a representation of the relationships between categories of data.

\section{Trustworthiness}

Quantitative research is evaluated for trustworthiness using criteria such as internal validity, external validity, reliability, and objectivity. However, "some qualitative 
researchers maintain that the canons or standards by which quantitative studies are judged are quite inappropriate to qualitative studies" (Strauss \& Corbin, 1990, p. 249).

Criteria that better fit the design of qualitative research include credibility, transferability, dependability, and confirmability (Lincoln \& Guba, 1985, chap. 11). Credibility refers to the extent to which the findings of an inquiry display a relationship with the reality of the phenomenon being investigated. Transferability concerns the applicability of the findings to other situations. Dependability addresses the extent to which the findings can be replicated in a similar inquiry. Confirmability is determined by the degree to which the findings can be agreed upon by a number of individuals.

Numerous techniques are described by Lincoln and Guba (1985, chap. 11) by which to meet these criteria. Techniques that this study employed include peer debriefing, member checks, thick description, dependability audits, and confirmability audits. Peer debriefing occurred as the analysis method and results of analysis were presented to thesis committee members for the purpose of evaluating clarity of research process and outcomes. Informal member checks, or the immediate verification of data and their interpretation by the informant from whom the data were obtained, occurred during interviews. A formal member check session, to which all informants were invited, was conducted to give informants the opportunity to critique the outcomes of analysis. Thick description was maintained through the provision of a wide range of information (including literature cited, interview transcripts, and records of analysis) such that the outcomes of research can at a later date be judged applicable or transferable to other contexts. This information was available to thesis committee members to perform dependability and confirmability audits as they felt necessary through the examination of the process by which the inquiry was undertaken to detect inconsistencies and inaccuracies. 


\section{$\underline{\text { Limitations }}$}

The goal of this study was not to compare naturopathic treatment to conventional treatment of menopause signs; rather, the goal of this study was to provide a qualitative understanding of naturopathic medicine from the perspective of women who use it. Information from this study is not intended to be used to evaluate the efficacy of naturopathic or conventional treatment of menopause signs.

The present study was confined to the experience of women who seek treatment for menopause signs from a provider of naturopathic medicine. Information generated from this study is not intended to draw conclusions about the menopausal population in general, or about menopausal women who seek treatment from other systems of health care.

\section{Point of view}

Qualitative methodology was selected for this study because it best fit the kind of knowledge sought. Although a rationale was presented to illustrate this fit, this rationale was not intended to demonstrate that one research method is superior to another. It was presented to demonstrate that grounded theory was an appropriate method by which to conduct an initial investigation of women's experience of naturopathic treatment during the menopausal transition.

In addition, this study is not intended for the purpose of comparing alternative medicine and conventional medicine for suitability in treating menopausal women. Further, this inquiry does not propose to advocate one perspective of menopause over another; rather, the goal of this study was to understand the lived experience of perimenopausal women who use naturopathic health care services and to discover how this experience fits, if at all, with the perspectives of menopause and the theories of alternative health care utilization presented in the literature review. The primary purpose of this study was to 
increase understanding of one health care alternative, naturopathy, and to do so by examining the experiences of women seeking naturopathic care for menopause signs. Theory generated about women's selection of naturopathic health care during the menopausal transition and increased understanding of women's experience of menopause may provide a basis for future studies about choices in health care and women's experience of menopause. 


\title{
CHAPTER IV
}

\section{RESULTS}

\author{
Informants
}

Sixteen women living in or near the Portland, Oregon metropolitan area and ranging in age from 37 to 61 (mean age was 51.8) were interviewed. All were Caucasian. Two had hysterectomies only, one had a hysterectomy and a partial oophorectomy, and one had a hysterectomy and a complete oophorectomy. Naturopathic treatment received by the women for menopause signs included diet, exercise, and nutritional supplement recommendations; counseling; botanical remedies; and hormones derived from natural and other sources. Additional informant characteristics are presented in figure 1.

\section{Findings}

Categories and subcategories as they pertain to the three areas of inquiry are listed in Figure 2. These categories and subcategories will be explained further in the following three sections. Of the following sections, the first three correspond with and contain findings from the three research questions, respectively. The fourth section describes 


\begin{tabular}{|c|c|}
\hline Number of informants ...........................16 & Informants' ages (mean age $=51.8$ ): \\
\hline 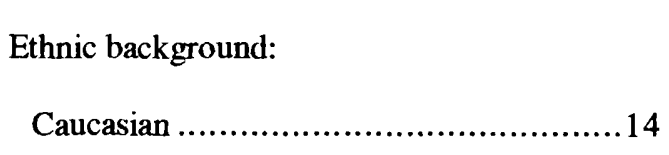 & 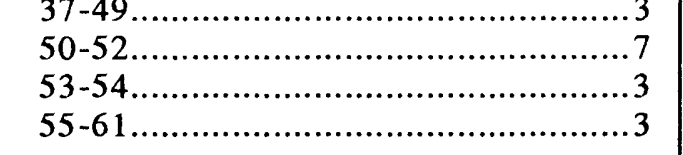 \\
\hline $\begin{array}{l}\text { Surgical status: } \\
\text { Hysterectomy only ..............................2 } \\
\text { Hysterectomy + partial oophorectomy ......1 } \\
\text { Hysterectomy + complete oophorectomy ...1 } \\
\text { No gynecological surgery........................12 }\end{array}$ & 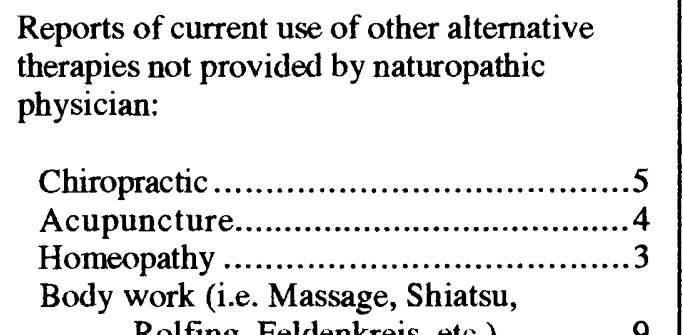 \\
\hline $\begin{array}{l}\text { Number of informants who have insurance } \\
\text { policies that cover naturopathic health care..3 }\end{array}$ & $\begin{array}{l}\text { None } \\
\text { *ther therapies used include osteopathy, } \\
\text { vitamins, vitamin therapy under supervision } \\
\text { of conventional physician, yoga, meditation, } \\
\text { visualization, herbs, and tai chi. }\end{array}$ \\
\hline 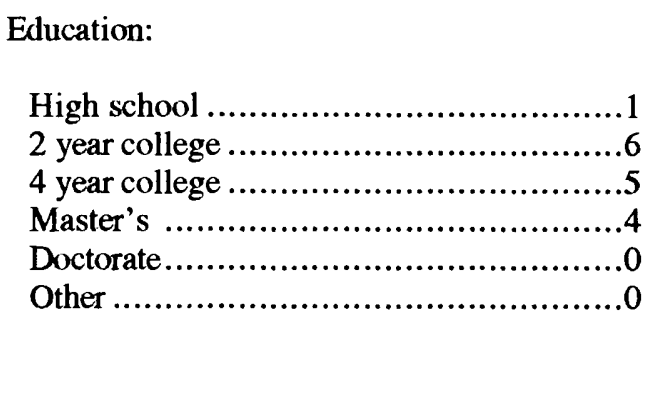 & $\begin{array}{l}\text { Approximate yearly income before taxes (in } \\
\text { dollars): } \\
\text { less than } 10,000 \ldots \ldots \ldots \ldots \ldots \ldots \ldots \\
10,000-20,000 \ldots \ldots \ldots \ldots \\
20,000-30,000 \\
30,000-40,000 \\
40,000-50,000 \\
\text { more than }\end{array}$ \\
\hline 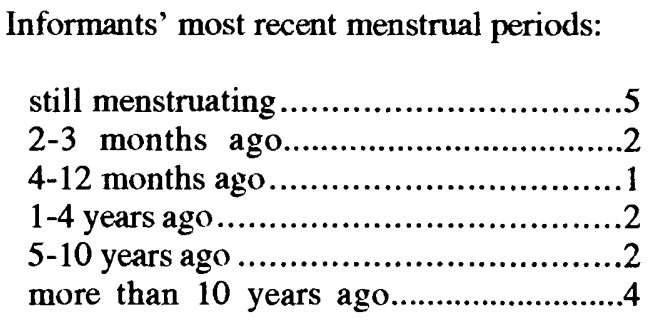 & 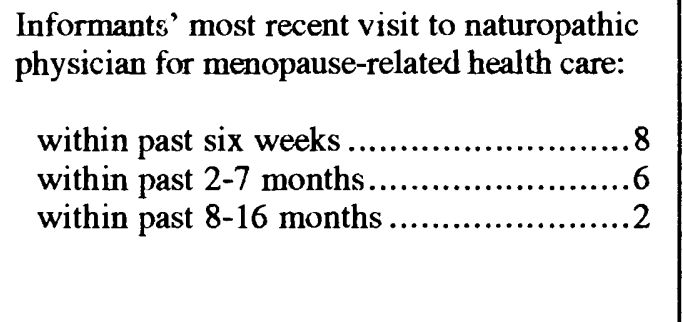 \\
\hline
\end{tabular}

Figure 1. Informant characteristics. 
(a) Why do women select naturopathic health care during the menopausal transition?

1. Practicing natural self-care

- healthy lifestyle

- avoiding the unnecessary use of drugs

- Prior use of alternative medicine

2. Rejecting the conventional medical system

- unsatisfactory results

- not compatible with practicing natural self-care

- does not provide moral or informational support

(b) Do women who use naturopathy for menopause-related health care share similar experiences of menopause?

1. It's not a singular event

- interrelatedness

- individuality

2. Paying attention to changes in and around me

3. Information helps

(c) Are women satisfied with the naturopathic treatment they receive for menopausal health care?

1. Naturopathy is consistent with practicing natural self-care

2. Naturopathy is effective in treating troubling menopausal signs

3. Naturopathy addresses individual and interrelated aspects of menopause

4. Naturopathy provides moral and informational support

Figure 2. Categories and subcategories as they pertain to the three areas of inquiry. 
relationships linking the three areas of inquiry. These relationships reveal an integrated perspective of women's use of naturopathic treatment for menopause signs. Finally, section five presents the emergent core category and specifies its role as a central phenomenon that integrates previously developed categories into the grounded theory.

Why do Women Select Naturopathic Health Care during the Menopausal Transition?

Conditions leading to the use of naturopathic treatment at menopause were represented by two categories of data: Practicing natural self-care and Rejecting the conventional system. Women who practiced natural self-care prior to menopause described their use of naturopathy for treatment of menopause signs as a choice consistent with their beliefs about health. For other informants, however, unsatisfactory experiences with the conventional health care system were the primary factor leading to use of naturopathic treatment at menopause.

Practicing natural self-care. "Natural" was a term used by the informants to describe preventive behaviors or remedies that arise out of what is found or expected in nature, as opposed to behaviors or remedies that are artificial or manufactured. "Natural" is a relative term; for example, though nutritional supplements aren't found in nature, their use for disease prevention was considered by the informants to be more natural than use of artificially produced drugs to combat disease. Conventional drugs synthesized from animal-derived hormones were considered less natural than remedies derived from plantbased hormones. "Natural" is also a subjective term; some individuals may find the use of highly technical medical intervention to be a natural part of the modern world. For the women of this study, however, "natural" implies less technical, less artificial means of maintaining health. "Self-care" is also a relative and subjective term. For some individuals, initiating contact with a provider of artificial medications and technical 
interventions at the time of illness may represent self-care. However, for the women of this study, self-care referred to taking steps to avoid the use of artificial medications by practicing preventive behaviors and making healthy lifestyle choices. For some informants, self-care also includes the use of natural, herbal, or home remedies when illness occurs.

The category Practicing natural self-care represents three subcategories: healthy lifestyle, avoiding the unnecessary use of drugs, and prior use of alternative medicine. A healthy lifestyle was characterized by an awareness of the importance of disease-preventive behaviors such as exercising and eating a well-balanced diet. Several women reported use of nutritional supplements: (Numbers in parentheses following quotes identify data source.)

Three times a week I do the jazzercise, and I take those calcium pills and I eat healthy food....I think that health is the most important thing. (5)

My mother...was a very sickly woman. And I looked at this and knew that I didn't want to go down this path....So I started seeking out alternatives and also assuming responsibility for my own health care very early in life.....and got into health, diet, vegetarianism. (8)

I was brought up in a home where we were concerned about...natural remedies. My parents were very health-minded, they had yogurt when it was not popular to even have yogurt....[My parents] saw doctors only when necessary...not for every little scrape and thing, therefore we were not pumped up with a lot of antibiotics...so just from a basic family standpoint of view we treated medication with very very serious implications. (6).

Women obtained information about natural self-care for menopause from various sources:

I seemed to be doing pretty good as long as I was taking vitamin $E$ and black current oil...sage and vitamin E I picked up on a radio talk show and just tried it to see if it would work. (4)

Recently a friend sent me some information...about a formula for...aging symptoms and the formula had wild yam which is the same thing that's in the formula that [my naturopathic physician] gave me for vaginal secretions. So I thought well that's pretty interesting. So there's crossovers. (9) 
Avoiding the unnecessary use of drugs was an important aspect of practicing natural selfcare:

It's not that I would never take a drug, but I tend to not, I just don't...go that route, and if it's necessary, ok, but if it's not I don't want to do it. (3)

I don't like drugs that I don't know what's going to happen to me. (2)

When asked specifically about avoidance of hormone replacement therapy, informants indicated that the use of hormones was not compatible with practicing natural self-care:

It seems very unnatural, very unnatural...this is a phase of life, this must be happening for a certain reason so why would we need to do [HRT]? (8)

In some cases, avoiding the unnecessary use of drugs was a practical matter of illness prevention. Allergies or negative reactions to medications used prior to menopause may have contributed to a woman's reluctance to consider conventional hormone replacement therapy during menopause:

I've used regular prescriptions and I've reacted to all of them....The progesterone was hormone-related, and thyroid was hormone-related, and I couldn't tolerate those, and I couldn't tolerate most antibiotics...penicillin finally broke me out, and a lot of the medications just make me feel like I'm really tense and ready to climb the wall....I had so much trouble with medications that it scared me to even think of taking medications. (13)

Several women had experience with naturopathic or other alternative medicine prior to using it for menopause-related treatment. Prior use of alternative medicine was associated with practicing natural self-care because alternative health care systems promote healthy lifestyles and avoid the unnecessary use of drugs. For several informants, prior use of alternative medicine was an important condition leading to the use of naturopathy for menopause-related health care: 
I was under a lot of stress with my aging grandmother, my mother, my aunt, and my sister who was dying of cancer....It was the same time my daughter was having a baby, and she says why don't you try a naturopath mother....[The naturopath] had got me through all the trauma of all these deaths and stuff....she helped me through all that, and so I've just kept with her.... (2)

I had a real bad problem and chiropractic wasn't working so I thought...I'd better find something else, and I talked to a friend...and she uses acupuncture and...the acupuncture took care of me...and her husband's the naturopath....So then it went from there...she said we can help you [with menopause]. (5)

Rejecting the conventional medical system. Informants may have chosen naturopathic medicine at menopause less because it was consistent with their beliefs about practicing natural self-care and more because they were dissatisfied with the conventional system of health care. Three subcategories represented reasons for dissatisfaction with the conventional system. Unsatisfactory results of conventional treatment for menopause or for a previous health matter was one reason for rejecting conventional treatment at or prior to menopause. Conventional medicine is not compatible with practicing natural self-care was a second reason for rejecting conventional treatment at or prior to menopause. Thirdly, informants may have rejected the conventional system because it does not provide moral or informational support.

Side effects of hormone replacement therapy was a common complaint of women who described unsatisfactory results of conventional treatment during menopause:

I didn't like the way the estrogen and progesterone were reacting to me, I mean I was reacting to this medicine. (5)

I just felt like there was something wrong....I felt full, bloated, slowing down, I was having a real hard time keeping up....Maybe a good way to put it is like I was just slowly being poisoned or something, I just felt like something wasn't right. (4)

One of the things that I was really discouraged about being on replacement therapy was continual periods....it just wasn't natural...we are meant to stop mensing at a certain time.... When I finally went off of the estrogen... what I found was I didn't have any headaches. (7) 
Unsatisfactory results of conventional treatment may have occurred for reasons unrelated to menopause:

I would go to a regular physician and he would say oh you have arthritis. He'd walk in the door, not examine me, and say you have arthritis. And so I would be getting worse and worse and worse and I would go to a different doctor and they would give me a different diagnosis, they would give me medication that had side effects that I did not like...but they weren't examining me..I was becoming paralyzed and wheelchair bound. I did not know it but I had [Lyme] disease.....I went to [the naturopathic physician]...he spent the time finding out what it was and I got treatment. (11)

Conventional treatment for menopause was also rejected because it was not compatible with practicing natural self-care:

I just have a real aversion to doing funny things to your body, I mean it's just not natural to put that kind of stuff in your body. (9)

[My conventional doctor] just said well let's just give you a hysterectomy. That was his solution. (11)

Finally, women who had previously practiced natural self-care or wished to practice natural self-care for menopause found the conventional health system did not provide moral support for this choice:

[My conventional doctor] said are you thinking of taking hormones and I said no. And she just looked at me and she said well why not? And I had to state my case! I had to fight for my rights! Because she was all hot to put me on hormones, so I just felt real bummed out by it and have right along about the medical approach. They don't seem to listen much. (9)

One woman who used conventional hormone replacement therapy felt she lacked informational support from the conventional medical system:

They put me on Premarin.....with very little guidance...I didn't really know what I was taking...I can remember right shortly after my [hysterectomy/oophorectomy] I had a real hard time with crowds of people, I began to withdraw. I could have had a lot of help from a doctor or from a group as to what to expect or how I should respond or what was normal 
and what was not normal. I was just given the pill, patted on the head and...you know, go on and have a beautiful life. (4)

Another woman with clear contraindications against the use of hormone replacement therapy (history of breast cancer) found that the conventional system was unable to provide information about alternative treatment for troubling menopause signs:

I went to see my gynecologist [because I was having tremendous hot flashes], my gynecologist sent me back to my oncologist, my oncologist sent me back to my gynecologist....I went back and forth and back and forth between the gynecologist and the oncologist so nobody was doing me anything at all. (12)

To summarize the results of analysis of data regarding the first research question, reasons for using naturopathy at menopause were represented by two categories of data: Practicing natural self-care and Rejecting the conventional medical system. Women tended to choose naturopathy because it was consistent with practicing natural self-care and because the conventional system was not satisfactory for menopausal or non-menopausal health care.

For some women, selecting naturopathy was clearly the result of experience pertaining to one of these categories; for others, choosing naturopathy was the result of experiences represented by both categories. A flow chart depicting four sequences of experiences arising from the data is presented in Figure 3. The underlined numbers indicate the first experience of a sequence; the arrows with solid points indicate the final experience of a sequence. Beneath the flow chart, the four sequences of experiences are described from the informants' point of view.

Figure 3 reflects an important relationship between the categories Practicing natural self-care and Rejecting the conventional system. Sequences 3 and 4, in which women had not practiced natural self care prior to their use of AM or NM, indicate that use of AM or NM resulted in practicing natural self-care: 


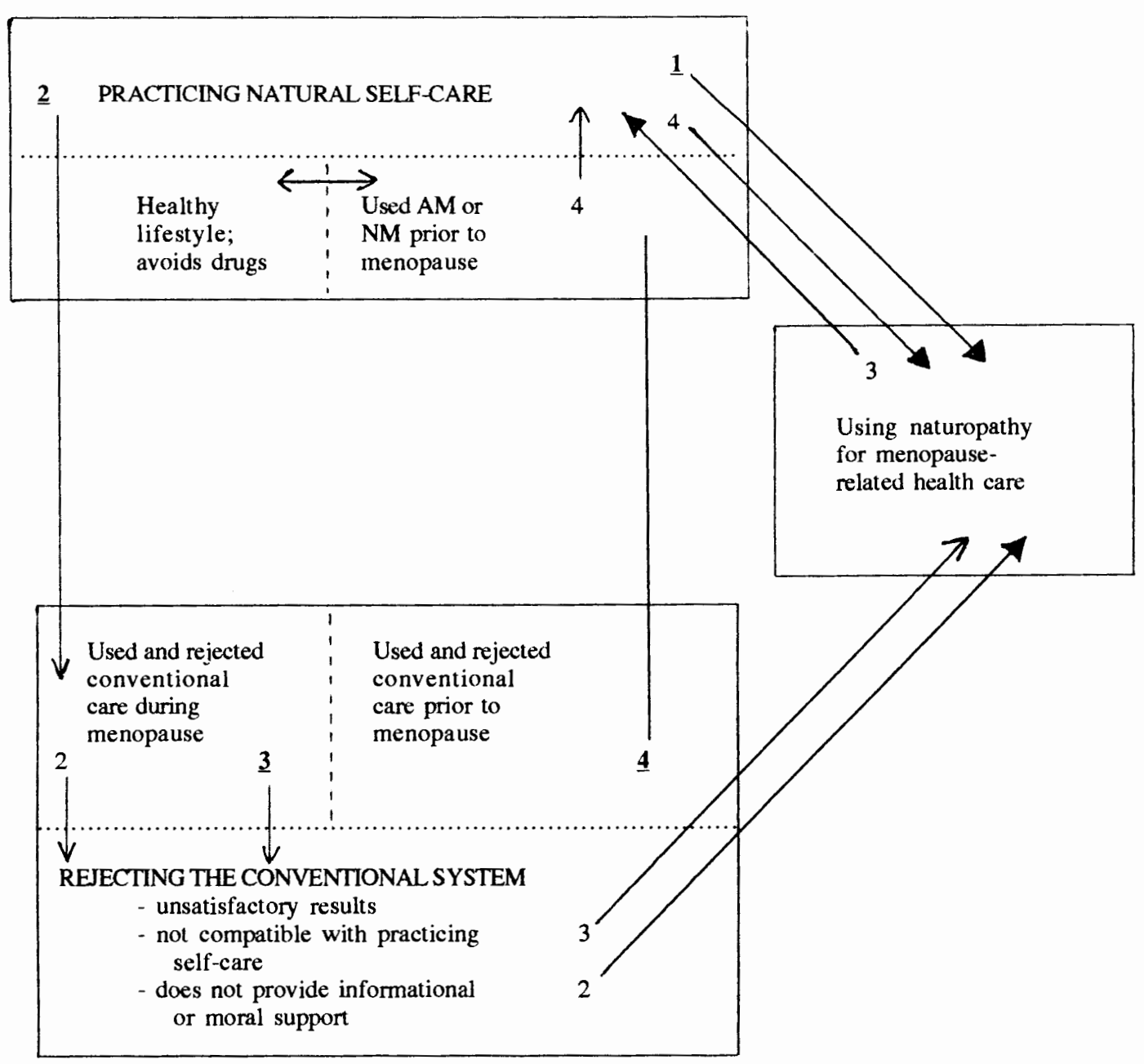

\section{Sequences of Experiences}

$1 \longrightarrow \rightarrow$ I use naturopathy at menopause because it is consistent with practicing natural self-care.

$2 \longrightarrow$ Even though I practice natural self-care, I used conventional treatment for menopause. Results of conventional treatment for menopause were unsatisfactory, so now I use naturopathy for menopausal health care.

$3 \longrightarrow$ Because I had always used conventional treatment for health eare, I used conventional treatment at menopause. Results of conventional treatment were unsatisfactory, so now I use naturopathy for menopausal health care. Using naturopathy at menopause resulted in practicing natural self-care.

$4 \longrightarrow \rightarrow$ I rejected the conventional medical system for reasons unrelated to menopause. This rejection led to use of alternative or naturopathic medicine. Use of altemative or naturopathic medicine resulted in practicing natural self-care. I use naturopathy at menopause because it is consistent with practicing natural self-care.

Figure 3. Sequences of Experiences pertaining to conditions leading to the use of naturopathic treatment for menopause-related health care. 
What I'm learning through [my naturopathic physician] is that...I need to learn to take care of myself....he hasn't given me a pill to be dependent on him, he's teaching me to be dependent upon myself. (11)

\section{Do Women who use Naturopathic Treatment for Menopausal Health Care Share Similar}

\section{Experiences of Menopause?}

The results of analysis of data regarding the second research question yielded no pattern of menopausal experience among this group of women. However, three categories emerged representing women's conceptualization of and response to this nonconformity: It's not a singular event, Paying attention to changes in and around me, and Information helps.

It's not a singular event. This concept suggests that there can be no accurate description of menopause representing all women's experience because menopause is an integrated aspect of a woman's midlife experience and cannot be examined in isolation from other life events. Although informants reported a variety of menopause signs including hot flashes, heavy bleeding, vaginal dryness, mood swings, and weight gain, these experiences were described in terms of their relationship to the women's life circumstances. For example, more than one woman described heavy bleeding, but the ramifications of the experience were unique for each of these women. Two subcategories, interrelatedness, and individuality, combine to form the concept that menopause is not a singular event for all women. Informants reported that the experience of menopause was interrelated to the circumstances of their lives:

I think another reason that I'm still having troubles with it is that I still have the young kids, so there's a part of me that says I have to stay young for these kids, and then my husband's older than I am, and he's retired, and he's into that thinking, so he's up here thinking oh we're old and retired, we have to slow down, and I'm sort of bouncing back and forth. (1)

There was a tremendous emotional stress...one of my friends and my cohorts who'd been working with me at the church went to another church and left me and as a musician you know this was really kind of a very 
emotional thing and that was very stressful, and then I was extremely stressed out with the business and working really really hard and bringing up three children, so it just kind of like all converged at that particular time and it just kind of made a snowball effect. (6)

Looking back on it I think it was just my life was too whacked out, too crazy. The business had just kind of taken off last summer and I was so stressed out trying to accept a different lifestyle. (9)

Because every woman has a unique set of life circumstances, each woman's experience of menopause is an individual experience:

I think probably my case might be a little bit unusual because of the handicap of my husband, because of the financial situation I've been put in, and the tremendous responsibility that I've been put in, I don't think just everybody has to deal with that. (4)

Each woman's experience is her own. And not a single one duplicates another one. Their history is not the same, we don't eat the same foods. Our temperaments are not the same. We're all, we might have similarities in areas but our whole menopausal experience is totally different from woman to woman. (6)

Paying attention to changes in and around me. Informants indicated that because there is a relationship between the experience of menopause and life circumstances, they could improve the menopause experience by paying attention to their external and internal environments:

If you could just simply pay attention, strict attention to your lifestyle and your diet and your exercise and just kind of, like I think I did when I was having babies, I was a little more free to just kind of concentrate on that and plan for the birth and that kind of stuff. (9)

I think I'm just more acutely aware now of the need to have time to myself. (8)

I think if it was just [my husband] and I, it would be so much easier, because I wouldn't have to deal with loudmouthed teenagers. (1)

The move up here was a great relief for me because we went from the hectic lifestyle of Los Angeles to the countryside of Washington....It's peaceful up here, it's calm....And when I came up here I determined to have a little bit more freedom, a little bit more time for me. And so I've had time to meditate, I've had time to study. (6) 
Paying attention to changes that occur during the menopause experience is related to natural self-care because practicing natural self-care is facilitated by a woman's awareness of the changes occurring in her body and her life:

I'm still trying to figure out when is the day going to come when I don't have to have these hot flashes. And this is a good time right now...I have 10 weeks of vacation from [work]. We'll just see if my hot flashes go down, I mean I'm not so busy, and I can sit and relax a little bit. (5)

Now I'm feeling so much more centered, and it's just a really amazing feeling. I've got my kid now on this bike trip....And my daughter who's home for the summer, and things are really settling down and I'm feeling like, I'm doing projects at home that make me feel good. (9)

Information helps. Paying attention to changes is a woman's way of gathering information about herself. Women of this study agreed that it was also important to be informed about menopause research and treatment options:

I wish that I had heard [the naturopathic physician's] presentation [at a menopause workshop] 5 years ago, because it laid it out so clearly, and she goes from the vitamins up to the estrogens from the [conventional] doctor, and I thought, you know if I'd had a plan, it might've been easier, because then I could see where I was going, but nobody else ever presented this plan to me, and it was very very good. So I'm sort of going backwards. (1)

Gathering information about other women's experience of menopause was also valued by the informants:

Having read other women's experiences helped tremendously....For instance the other night I was reading the book The Pause by Lonnie Barbach, and certain things that she was explaining in there were going, $\mathrm{Oh}$ why that's what that's all about! You know? I didn't even know that. It's a gradual, informational thing. Up until the point that I began experiencing menopause I didn't want to know anything about it....So it's all about understanding, having enough information, talking about it to other girls who are also going through it, and just realizing that you know, you're going to be fine. Just knowing you'll be okay. (6) 


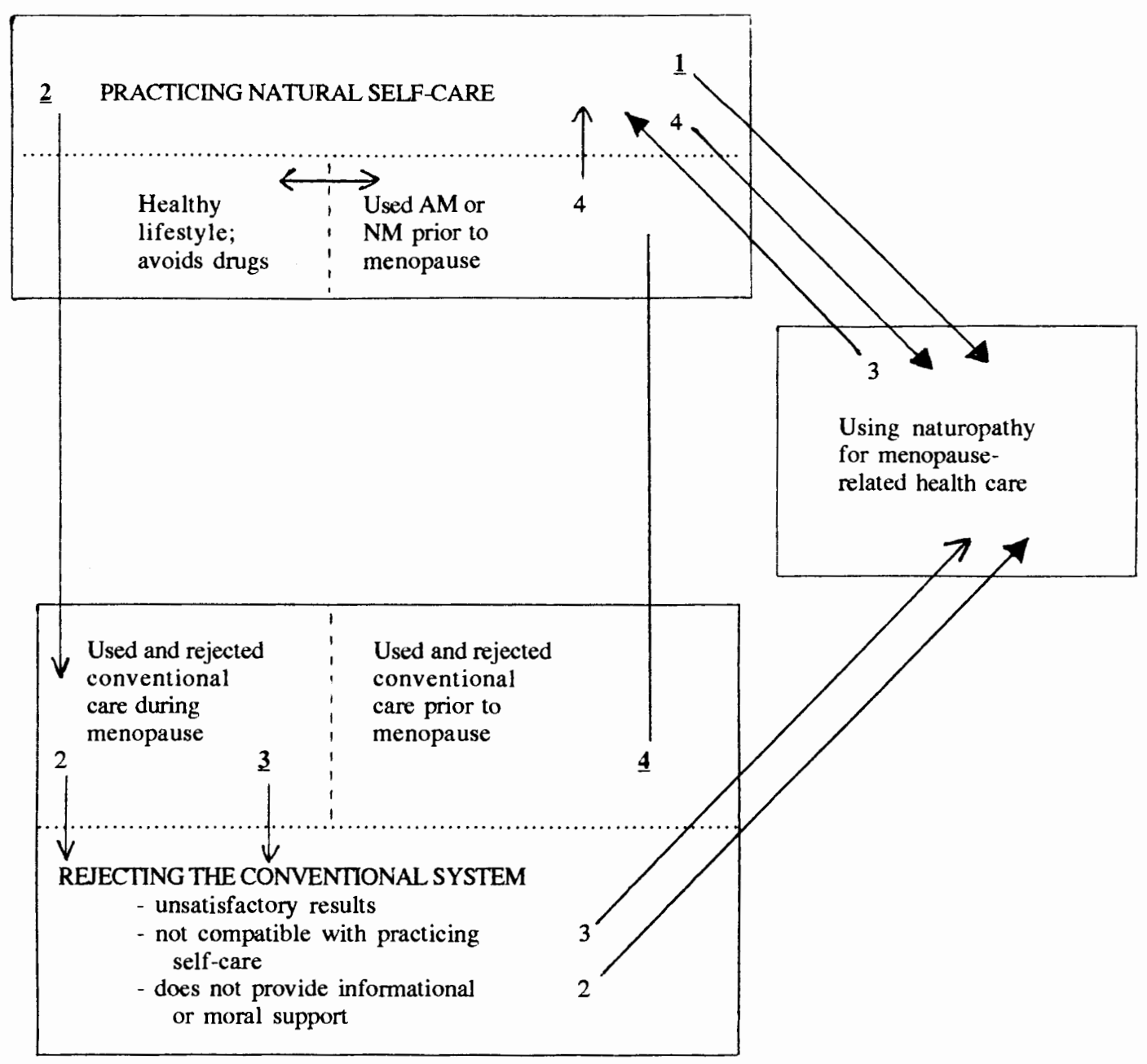

\section{Sequences of Experiences}

$1 \longrightarrow \rightarrow$ I use naturopathy at menopause because it is consistent with practicing natural self-care.

$\underline{\mathbf{2}} \longrightarrow \quad$ Even though I practice natural self-care, I used conventional treatment for menopause. Results of conventional treatment for menopause were unsatisfactory, so now I use naturopathy for menopausal health care.

$3 \longrightarrow$ Because I had always used conventional treatment for health care, I used conventional treatment at menopause. Results of conventional treatment were unsatisfactory, so now I use naturopathy for menopausal health care. Using naturopathy at menopause resulted in practicing natural self-care.

$\underline{4} \longrightarrow \rightarrow$ I rejected the conventional medical system for reasons unrelated to menopause. This rejection led to use of alternative or naturopathic medicine. Use of alternative or naturopathic medicine resulted in practicing natural self-care. I use naturopathy at menopause because it is consistent with practicing natural self-care.

Figure 3. Sequences of Experiences pertaining to conditions leading to the use of naturopathic treatment for menopause-related health care. 
Naturopathy is effective in treating troubling menopause signs. Informants reported satisfactory results from naturopathic treatment for menopause signs such as hot flashes and mood swings:

As long as I exercise regularly and I take those pills once a day, I'm pretty even-steven, and I don't seem to get out of whack. (2)

If I don't take the flax and the zinc...[the hot flashes] just [come] right back....It's just what my body needs, I guess. (5)

I would cry for no reason at all, and I would sit and try to figure why am I crying?...And it was the stupidest, dumbest thing, because I am a very happy person, I am an outgoing, loving, very productive person and here was this Whaa!....And much less of that after being on the naturopathic [treatment]. (6)

I do think it has helped.... think it's very subtle and it's hard to know what leads to what, but I'm sure the herbal treatment has helped me to settle down a little better. (9)

Many informants pointed out that they didn't get instant success with naturopathic treatment:

I started there a year ago, and we experimented with all different things...it took about ten months to figure out...you just can't go in and snap, this is it...you know it was sort of frustrating but I kept going. Kept trying. (5)

Others, at the time of interview, were still working with their naturopathic physician to obtain satisfactory results:

For me it's been a very difficult time trying to find something that would work where I don't have hot flashes and night sweats..... [My naturopathic physicians] have really worked really really hard trying to find something that was workable for me. (4)

Naturopathy addresses individual and interrelated aspects of menopause.

Quick results are not what women may have been searching for. Naturopathy takes time to find the best treatment for each woman. Informants accepted this process because they were satisfied that naturopathy addressed their individual experience of menopause: 
It's really really nice to have a doctor who's concerned about treating the whole person and she realizes that psychologically a lot of what a woman goes through in menopause is just as important as physical. (6)

They look at the whole person. And they make you feel...very comfortable. They want to know about you as a person, they want to know your family life, they want to know how stress plays a role in it....[I've been to other physicians where] I felt like I was being ran in and ran out, and if the tests didn't show anything they knew nothing about me. I was recommended to go to a psychiatrist [before I was diagnosed with chronic fatigue syndrome] probably more times than not when I would go in and explain the symptoms to these doctors...they would belittle me...I just did not feel very comfortable at all. (12)

Naturopathy provides moral and informational support. Informants value the moral and informational support they get from the naturopathic health care system. They feel that their naturopathic physician is supportive, welcomes questions, and provides information:

I feel like I could talk to her about anything. (12)

What I like about this naturopath is that...it's just the positive attitude helps me....It helps to be positive about it...and stop fighting it. (5)

At times...I've gone in for an office visit and sometimes we have only just talked...over symptoms or problems or discussed things and I feel she's very thorough in that she wants to treat the whole person. And at times she's recommended a book, or information or given me information, or a different outlook on some aspect.... One time she recommended a book and I went out and bought it and it was exactly what I needed at that moment. (6)

I've only been seeing [my naturopathic physician] for about eight months, and so I still am subject to reading those things [in the paper about research concerning 80 year old women in nursing homes who are on estrogen and don't have Alzheimer's disease] and getting alarmed, but you know I'll call him and he answers all these questions. Even if it's seven o'clock at night he'll call me at home. Oh, Hi! Isn't that neat? (14)

The atmosphere in the practitioner's office was important to at least one informant:

Everybody's on a first name basis, it's small, you know everybody in the office, I feel so much more comfortable, they don't have the... white smocks, I can call my doctor [by her first name] and I'm a person there, and I feel when I go to the large [conventional] clinics I am...an object which 
has all of these parts put together and one part is treated at a time and I don't feel I'm listened to so I just think there's a world of difference. (7)

Although informants frequently explained that they selected naturopathic health care at menopause because it offered features they found lacking in conventional health care, they also related positive experiences with conventional physicians. Women described conventional physicians who approved of natural self-care and alternative medicine, who did not immediately recommend artificial, technical, or invasive treatments, and who welcomed questions and provided appropriate information. The data does not support the notion that all conventional physicians lack certain qualities that alternative practitioners possess. Rather, the data indicates that the informants, who hold these qualities in high regard, had significant experiences with conventional physicians who did not possess these qualities or were unable to express them due to time constraints or other difficulties. Several informants explained that they liked using both conventional and alternative health care.

There were no data representing patterns of dissatisfaction with naturopathic treatment for menopause signs. Individual concerns included the high price of nutritional supplements that are sold at the naturopathic physician's office (the informant indicated they are less expensive at her local shopping center), an unsatisfactory appointment (attributed to an "off-day" for the naturopathic physician), and weight gain felt to be the result of the naturopathic treatment. One woman indicated that satisfactory treatment was the result of finding a suitable gynecologist who just happened to practice naturopathy. Two women, when asked if they were satisfied with naturopathic treatment of menopause signs, indicated that it's "as good as it is going to get" (1), or that she was " $80 \%$ happy" (5) with the results of treatment. Both of these informants had used and rejected conventional hormone replacement therapy because of side effects prior to using naturopathy. 
The Experience of Women who Choose Naturopathic Health Care During the Menopausal Transition: An Integrated Perspective

Relating categories from one area of inquiry to another is the first step toward integrating data into a conceptual framework that represents the experience of women who use naturopathy at menopause. The results of analysis of data pertaining to the third research question can be viewed in relationship to the first and second research questions. In Figure 4, categories representing satisfaction with naturopathic treatment during menopause can be matched with categories representing conditions leading to the use of naturopathy and categories representing women's experience of menopause. As informants rejected the conventional system because it was not consistent with their values and beliefs about practicing natural self-care, it follows that they were satisfied with naturopathy because it was consistent with their values and beliefs about practicing natural self-care. Similarly, as informants felt that the experience of menopause was intricately related to the circumstances of their lives, it follows that they were satisfied with naturopathy because treatment for menopause signs addressed interrelated and individual issues; and as informants found information about menopause and self-care to be beneficial, it follows that they were satisfied with naturopathy because it provided information about menopause and self-care. Further relationships between categories generated from the three areas of inquiry are depicted in figure 4.

\section{Core Category: Exchanging Information}

Categories and subcategories representing the importance of information as it relates to conditions preceding informants' use of naturopathy at menopause, informants' experience of menopause, and informants' satisfaction with naturopathic health care at 


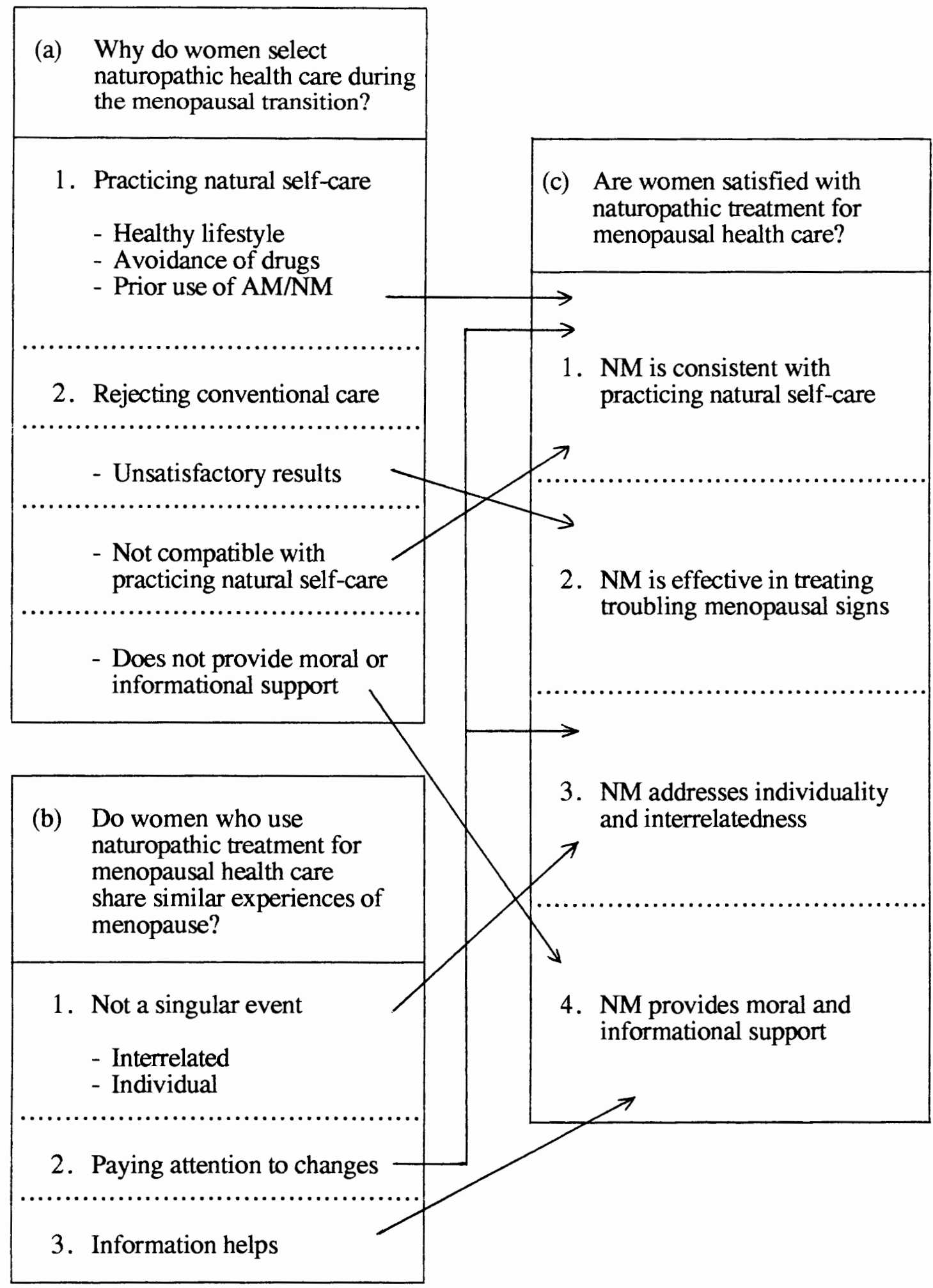

Figure 4: The experience of women who choose naturopathic health care during the menopausal transition: an integrated perspective. 
menopause have been described above. Continued analysis of these and other categories resulted in a more abstract conceptualization of data leading to the emergence of the core category Exchanging information. The nature of the relationships between categories as they pertain to Exchanging information is indicated in Figure 5 from the point of view of the women who served as sources of data.

Figure 5 applies the components of the coding paradigm described above (Corbin and Strauss, 1990; Strauss, 1987) as a framework for relating the core category (Exchanging information) to the central phenomenon (women selecting naturopathic health care during the menopausal transition). The column headings (Conditions, Interactions, Strategies, and Consequences) specify stages of experience surrounding the central phenomenon. Each row represents a sequence of experiences described by the informants of this study. The first cell of each row identifies major categories of data pertaining to conditions associated with the central phenomenon (including categories of data representing menopause experience). The second cell of each row describes the characteristics of information exchanged during interactions with conventional or naturopathic physicians. The third cell of each row describes information gathering strategies that informants employed to improve the menopausal experience and optimize naturopathic health care during menopause. The fourth cell of each row identifies the consequences resulting from such interactions and strategies. Thus, Figure 5 provides a representation of the sequence of experiences described by women who use naturopathy at menopause: Conditions provide the context for interactions and strategies based on the basic premise that exchanging information (of certain interactional characteristics and on varying strategic levels) is essential to a satisfactory menopause experience and to the success of naturopathic health care during menopause. The exception to this sequence of experiences is the case in which the primary condition leading to use of naturopathy is 


\begin{tabular}{|c|c|c|c|c|}
\hline & 1 & 2 & 3 & 4 \\
\hline & CONDITIONS & $\begin{array}{l}\text { INTERACTIONS } \\
\text { Exchanging information }\end{array}$ & $\begin{array}{l}\text { STRATEGIES } \\
\text { Exchanging information }\end{array}$ & CONSEQUENCES \\
\hline A & I practice natural self-care. & $\begin{array}{l}\text { My naturopathic physician provides me } \\
\text { with information about practicing } \\
\text { natural self-care in general and for } \\
\text { menopause. }\end{array}$ & $\begin{array}{l}\text { I keep myself informed about practicing } \\
\text { natural self-care in general and for } \\
\text { menopause. }\end{array}$ & $\begin{array}{l}\text { I am satisfied with naturopathic health } \\
\text { care at menopause because it is } \\
\text { consistent with practicing natural } \\
\text { self-care. }\end{array}$ \\
\hline B & $\begin{array}{l}\text { I rejected the conventional medical } \\
\text { system for menopause-related } \\
\text { health care. }\end{array}$ & $\begin{array}{l}\text { My conventional physician did not } \\
\text { provide me with information that } \\
\text { supported my health values or was } \\
\text { relevant to my circumstances. My } \\
\text { conventional physician disregarded } \\
\text { relevant information about my } \\
\text { individual circumstances. }\end{array}$ & $\begin{array}{l}\text { Information offered by my conventional } \\
\text { physician about treatment options was } \\
\text { limited. }\end{array}$ & $\begin{array}{l}\text { Naturopathic treatment of my } \\
\text { troubling menopause signs is } \\
\text { effective and has fewer side effects } \\
\text { than conventional treatment. }\end{array}$ \\
\hline $\mathrm{C}$ & $\begin{array}{l}\text { For me, menopause is not a singular } \\
\text { event. }\end{array}$ & $\begin{array}{l}\text { My naturopathic physician gathers } \\
\text { information about my individual } \\
\text { circumstances. }\end{array}$ & $\begin{array}{l}\text { I believe that to effectively treat } \\
\text { troubling menopause signs, my } \\
\text { physician must be informed about the } \\
\text { individual circumstances of my life. }\end{array}$ & $\begin{array}{l}\text { I am satisfied with naturopathic health } \\
\text { care at menopause because it addresses } \\
\text { interrelated and individual concerns. }\end{array}$ \\
\hline $\mathrm{D}$ & $\begin{array}{l}\text { Paying attention to changes in and } \\
\text { around me improves my menopause } \\
\text { experience. }\end{array}$ & $\begin{array}{l}\text { I can help my naturopathic physician to } \\
\text { treat my troubling menopause signs by } \\
\text { providing information about changes I } \\
\text { experience in my body and my life. }\end{array}$ & $\begin{array}{l}\text { Gathering information from my body } \\
\text { and my life helps me to practice natural } \\
\text { self-care for menopause. }\end{array}$ & $\begin{array}{l}\text { I am satisfied with naturopathic health } \\
\text { care at menopause because it is } \\
\text { consistent with practicing natural } \\
\text { self-care. }\end{array}$ \\
\hline $\mathrm{E}$ & $\begin{array}{l}\text { Being informed improves my } \\
\text { menopause experience. }\end{array}$ & $\begin{array}{l}\text { My naturopathic physician provides me } \\
\text { with information about menopause. } \\
\text { Exchanging information with other } \\
\text { women led me to use naturopathy at } \\
\text { menopause. I encourage other women to } \\
\text { try naturopathy for menopause. }\end{array}$ & $\begin{array}{l}\text { The experience of menopause is } \\
\text { improved when } 1 \text { gather information } \\
\text { about menopause from formal and } \\
\text { informal sources. }\end{array}$ & $\begin{array}{l}\text { I am satisfied with naturopathic health } \\
\text { care at menopause because it provides } \\
\text { informational and moral support. }\end{array}$ \\
\hline
\end{tabular}

Figure 5: Women who use naturopathy at menopause: Exchanging information 
rejection of the conventional medical system (row B). In this sequence, interactions and strategies preceded conditions which, in turn, led directly to the use of naturopathic medicine. A representation of the sequence of experiences in this case is as follows: Inadequate information exchange (due to unsatisfactory interactional characteristics or inappropriate strategic levels) contributes to conditions leading to the use of naturopathic health care during menopause.

As indicated in Figure 5, the core concept, Exchanging information, is an aspect of all major categories of data and their interrelationships, and is the foundation of a theoretical model representing the experience of women who use naturopathic health care at menopause. Figures 3 and 5 provide a basis for the development of the following narrative layout of the grounded theory.

\section{Narrative Layout of the Grounded Theory}

Women who choose naturopathic medicine for health care during the menopausal transition practice natural self-care. Practicing natural self-care is characterized by any combination of the following behaviors: eating nutritious foods to prevent disease, use of nutritional supplements to prevent disease, exercising to prevent disease, avoiding the unnecessary use of artificial drugs and technical medical procedures, and utilizing the services of alternative health care providers. Practicing natural self-care is promoted by interactions and strategies initiated by women to maximize transmission of appropriate and relevant information about practicing natural self-care. Interactions with conventional and alternative practitioners, the media, friends, family, and other sources of information provide support for practicing natural self-care. Women who use naturopathy at menopause fall into two groups: those who have a history of practicing natural self-care, and those who practice natural self-care as a result of using alternative medicine. 
Women who have a history of practicing natural self-care use naturopathy at menopause because the naturopathic approach to health is consistent with practicing natural self-care and offers information about and access to alternatives to synthetic drugs and technical medical procedures (Figure 3, sequence 1; Figure 5, row A). Prior to using naturopathy at menopause, they may have already used alternative medicine for health matters unrelated to menopause. For women who have a history of practicing natural selfcare, choosing naturopathy is less a rejection of conventional treatment and more a choice consistent with practicing natural self-care. Practicing natural self-care does not preclude a woman who is experiencing troubling, unmanageable menopause signs from seeking and using conventional treatment such as hormone replacement therapy (Figure 3, sequence 2). However, unsatisfactory results of conventional treatment at menopause due to poor results or side effects, incompatibility with practicing natural self-care, or lack of information about or support for alternatives to HRT contributes to conditions leading to subsequent use of alternative treatment for menopause signs. These women who practice natural selfcare and have used conventional treatment at menopause attribute their selection of naturopathy at menopause to both practicing natural self-care and rejecting the conventional system.

Women who practice natural self-care as a result of using alternative medicine choose naturopathy at menopause because previous use of conventional treatment at or prior to menopause was unsatisfactory due to poor results or side effects, incompatibility with practicing natural self-care, or lack of information about treatment options (Figure 5, row B). Subsequent use of alternative medicine provided them with information about and incentives toward practicing natural self-care (Figure 3, sequences 3 and 4). These women attribute their use of naturopathy at menopause to a rejection of the conventional medical system. 
The menopausal experience of women who use naturopathy at mid-life is intricately related to the circumstances of their lives and is thus a unique, individual experience. These women, consistent with practicing natural self-care, take responsibility for their wellbeing at menopause by paying attention to the changes that are occurring in their bodies and their lives. They value a variety of information about menopause, including information about changes occurring in all women at menopause, information about options in treatment for menopause signs, information about self-care during the menopausal years, and information from other women about their experiences of menopause. Formal information from health care providers such as workshops or presentations about menopause as well as informal exchanges with women who are also perimenopausal or postmenopausal are valued by these women. Gathering such information helps women to make sense of their own experience, thus rendering it more positive than it would be without access to such information (Figure 5, rows $\mathrm{C}$, D, and E).

Women who use naturopathy at menopause cite four primary reasons for satisfaction: naturopathy is consistent with practicing natural self-care (Figure 5, cell 4A and 4D), naturopathy is effective in treating menopause signs (Figure 5, cell 4B), naturopathic physicians address interrelated and individual concerns (Figure 5, cell 4C), and naturopathic physicians provide moral and informational support (Figure 5, cell 4E). Satisfaction with naturopathic health care during the menopausal transition occurs not only because treatment is effective but also because women's values, attitudes, and beliefs are respected and reinforced by the naturopathic approach to health care. 


\section{CHAPTER V}

\section{DISCUSSION}

The grounded theory that emerged from this study indicates that women who use naturopathic medicine at menopause practice natural self-care and experience menopause as a complex, interrelated outcome of social, psychological and biological factors. For these women, a health care practitioner who reinforces health values and beliefs associated with natural self-care and addresses interrelated and individual aspects of menopause is instrumental in achieving satisfactory treatment during the menopausal transition. Women are satisfied with naturopathic health care at menopause because a high degree of information exchange between patient and physician supports practicing natural self-care and facilitates treatment of social, psychological, and biological aspects of menopause. Women who use naturopathic medicine during the menopausal transition indicate that obtaining information from their naturopathic physician, books and other media, and other menopausal or post-menopausal women helps them to sort out the complexity of their menopause experience, thus making it a more positive experience.

The grounded theory developed in this study may be of use to health educators and health care providers by increasing knowledge about treatment options for women at menopause. Further, the theory may assist health educators and providers to identify perimenopausal women who are likely to benefit from naturopathic treatment. Although the theory developed in this study is specific to women who use naturopathy at menopause, 
components of the theory may be used to explore aspects of other alternative medicine and menopause research, and may be used as a basis for future research in these areas. The following sections address the findings from this investigation as they relate to these areas of study.

\section{Alternative Medicine}

Research cited in the literature review identifies several motivating factors contributing to patients' use of alternative medicine. This study provides theory about how these motivating factors arise out of patients' experience of illness and treatment. All of the factors identified in the literature review (dissatisfaction with conventional medicine; seeking a solution to a health problem; beliefs about health, illness, and treatment; and psychological needs) appear to be relevant to the experience of women interviewed for this study. Two of these factors appear to be especially significant: dissatisfaction with the conventional system, and beliefs about health, illness, and treatment. In examining the theory generated from this study, it can be seen that these two motivating factors are linked by a single commonality: interaction between patient and physician. According to the theory, negative interactions between patients and their conventional physicians contributed to dissatisfaction with conventional treatment, and positive interactions between patients and their naturopathic physicians reinforced beliefs about health, illness, and treatment.

Although opinions about philosophical, diagnostic, and treatment differences between naturopathic and conventional health care were expressed by the women interviewed, the area of difference most frequently described by the women was the patient-physician relationship. The patient-physician relationships described by the 
informants were characterized by levels of information exchange. Two aspects of patientphysician information exchange invite further exploration: quality of information and transmission of information. Quality of information refers to the type of information that the women of this study were seeking at the time of their menopausal transition. In the informants' experience, conventional physicians provided little information about self-care or alternatives to hormone replacement therapy. Instead, conventional physicians offered information based on a model of menopause that emphasizes hormonal changes and deemphasizes the psychological component of menopause. Further study exploring quality of information exchanged between patients and their conventional or alternative physicians would provide additional insight into this aspect of the patient-physician relationship.

Transmission of information refers to the manner in which information is passed from physician to patient. McCann and Blossom (1990) advocate patient education strategies that are based on the principle of andragogy rather than pedagogy.

In the pedagogic model, the relationship between the teacher and learner is based on authoritative expertise. The teacher's role is to determine the nature and scope of the educational program and then to instruct the passive, cooperative learner. In the andragogic model, the teacher-learner relationship is one of mutual participation. The teacher's role is to facilitate, promote, and encourage the learner's active involvement in developing and planning the educational program. (p. 44)

McCann and Blossom suggest that patients may object to a physician's authoritarian, paternalistic approach. "It can lead to resentment, resistance, and, ultimately, to [the patient's] changing physicians in hopes of finding one who relates to them in a more egalitarian manner" (p. 48). McCann and Blossom recommend that physicians use strategies that encourage active involvement of the patient, explore the patient's attitudes and beliefs, identify the patient's strengths and limitations, and address the patient's concerns and issues. Additionally, they advise physicians to inform the patient of treatment options and consequences, elicit treatment preferences of the patient, and attempt to resolve 
patient-physician differences. The grounded theory that emerged from this study suggests that women are satisfied with naturopathic treatment at menopause because naturopathic physicians adopt an andragogic style of exchanging information and prescribing treatment.

In reviewing empirical studies concerned with the relationship between the alternative practitioner and his patient, Hewer (1983) found that

the application of alternative methods involves a considerable amount of time spent on the individual patient....[and] the alternative practitioner seems to consider the needs of his patients exceptionally well, which means that his activities are very much 'patient-oriented.' (p. 176)...There is sufficient evidence for the assumption that the therapeutic relationship between the alternative practitioner and his patient is characterized by a remarkable psychological value. (p. 178)

Research cited earlier in this study suggests that users of alternative medicine possess a higher incidence of psychological problems than non-users of alternative medicine. It may be that users of alternative medicine are not psychologically unbalanced; rather they have greater sensitivity to the relationship between psychological dimensions of health and healthy physical functioning. The informants of this study indicated that their naturopathic practitioners were effective in addressing psychological aspects of menopausal health because they gathered from their patients information necessary to understand the psychological factors affecting the individual experience of menopause. Perhaps alternative medicine users do not suffer from a higher incidence of psychological problems, but rather suffer from a higher incidence of experiences with conventional physicians who do not address the psychological dimension of health.

Though not occurring often in the interview transcripts, several informants provided descriptions of experiences with conventional physicians who either were supportive of their selection of alternative medicine or were instrumental in helping them find effective alternative treatment. Most of the informants, however, learned about alternative or naturopathic medicine from family, friends, or other non-medical sources. 
Finding ways to assist conventional physicians in recognizing when alternative treatment may be appropriate would be beneficial. Christie (1991) describes a "dialogue group" consisting of conventional and alternative practitioners formed in Norway to bring different kinds of practitioners closer; to let them meet as
professionals and as human beings whose primary goal is to help patients.
It was also to help avoid confrontations and 'wars' and to try to create
understanding and respect between practitioners of the two types of
medicine. Another purpose was to let them hear and experience what other
professionals might be able to do in trying to help patients, and perhaps
even to start to cooperate for the good of the patients. (p. 551)

The two conditions leading to use of naturopathy that emerged from the study (naturopathy's alignment with patients' values and beliefs about practicing natural self-care, and rejection of the medical system) are linked by the patient-physician relationship. In the first case, patients attribute use of NM to valued naturopathic patient-physician interaction; in the second, they attribute use of NM to devalued conventional patient-physician interaction. The difference between these attributions may be less a result of differences in women's experience and more a result of differences in their perceptions of existing individual and professional attitudes toward alternative medicine. Women who wish to explore alternative treatments may perceive that conventional physicians view them as noncompliant and feel compelled to defend their choice by describing negative experiences associated with HRT that are understood by most conventional physicians instead of describing positive experiences associated with alternative treatment that are understood by few conventional physicians. Questioning a woman's informed judgement may further add to psychological difficulties sometimes faced by menopausal women who opt to use alternatives to hormone replacement therapy. Visser, Peters, and Rasker (1992) suggest that increased understanding of alternative medicine by conventional physicians may improve the conventional patient-physician relationship. "Having an open mind towards 
alternative medicine might have something to do with a doctor-patient relationship in which not only somatic aspects of the disease have a place" (p. 489).

An additional aspect of health care limitations imposed by the dominant conventional medical system emerged from the analysis of interview transcripts. Several women interviewed discussed insurance coverage when describing factors related to their selection of menopause-related health care. They pointed out that naturopathic health care at menopause was so important to them that they were willing to experience financial inconvenience or difficulty when their insurance did not pay for naturopathy. Other women indicated that lack of insurance coverage of alternative medicine was a barrier to its use for health matters other than menopause, and that only because it was paid by insurance did they use conventional medicine for routine gynecological health care. Coverage of selected alternative medicines in all insurance plans would help to meet the growing demand for increased options in health care.

A further consequence of the dominance of the conventional Western medical system in our country is the loss of the role of women as bearers of information about health in general and women's health in particular, including menopausal health. This concept will be discussed in the following section.

\section{Menopause}

In modern Western societies, it is becoming less common to find women who live in proximity to their mothers, aunts, grandmothers and other traditional sources of information about menopause and self-care. Consequently, women must turn to the medical system for information and support. Health care providers who offer information 
based less on the modern biomedical perspective of menopause and more on an integrated, experiential perspective of menopause are used by women who value traditional sources of health and self-care information. McElmurry and Huddleston (1991) reviewed research on menopause and self-care and found that

in becoming more involved in their own health care, women are reassuming more responsibility for their own welfare.... Health providers who value self-care will assist women by teaching self-care and related pertinent information as needed and by helping women to explore their options and choices." (p. 17-18)

The women of this study expressed eagerness to transmit information they learned from their naturopathic physician to other women. They encouraged other women in their age group to use naturopathy for troubling menopause signs. They expressed concern for women who might benefit from, but lack information about, naturopathic health care at menopause. They were enthusiastic about books they had read and expressed their pleasure at the increased availability of popular information about menopause and natural self-care practices. Use of alternative medicine at menopause and women's eagerness to transmit related information is consistent with the goal of the Women's Health Movement to disseminate information to women that increases the understanding of their bodies and empowers them to make appropriate, informed decisions about medical care (National Women's Health Network, 1989). Increased availability of information about menopause and self-care through seminars, workshops and quality patient-physician relationships that enhance sharing of knowledge among women may represent a return to traditional patterns of health-related information exchange among women. This trend may parallel the increasing interest in the study of women's role in folk medicine traditions (Achterberg, 1990; McClain, 1989).

Several of the women interviewed indicated that it was important to have a female physician, whether conventional or alternative. Some felt this to be of particular 
importance for gynecological and menopausal health care. However, some of the women interviewed were patients of male naturopathic physicians. One of these women insisted that, following her negative experiences with male conventional physicians, she would never again be the patient of a male physician. When it was pointed out to her that her naturopathic physician was a man, she replied, "I've learned to trust this person." The positive attributes she valued in female physicians were exhibited by her male naturopathic physician as well. There is growing interest in understanding differences in interactive styles of male and female physicians (West, 1993). Differences in male and female therapeutic styles may parallel differences in conventional and alternative therapeutic styles. Further exploration of the relationships between male, female, conventional, and alternative therapeutic styles would increase health care providers' ability to meet patient needs and preferences.

The literature review of this study outlined biomedical, sociocultural, and Women's Health Movement perspectives of menopause. Of the three perspectives of menopause presented in the literature, the experiences described by the informants were most consistent with the sociocultural and Women's Health Movement perspectives. The sociocultural perspective utilizes and transmits information about women's psychological, social, and cultural circumstances at midlife. The Women's Health Movement perspective utilizes and transmits information about normal menopausal experience and self-care practices. The experiences described by the informants were least consistent with the biomedical perspective, which utilizes and transmits information about hormonal changes associated with menopause. Similarly, conventional medicine and naturopathic medicine utilize and transmit different types of information. The women of this study may not have been selecting a particular treatment exclusive to naturopathic medicine (and, as pointed out earlier in this study, many recommendations made by naturopathic physicians converge 
with recommendations made by conventional physicians), but instead may have been selecting a health practitioner who utilized and transmitted information that was consistent with the patients' menopausal experiences and health beliefs. The women of this study did not indicate that biomedical information offered by their conventional practitioners was unimportant, rather they indicated that information about sociocultural and experiential aspects of menopause was not available from their conventional practitioner.

That menopause was a natural developmental process (and not a disease state) was implicit in interview transcripts. The meaning these women ascribed to menopause was embedded in their personal experience and expressed as a desire to understand menopause more fully through increased exchange of information with their health care practitioner and with other women. Further, that the informants of this study identified the meaning of menopause as a developmental process and the experience of menopause as an outcome of interrelated factors is not surprising, since this view is consistent with the naturopathic view of menopause.

Finally, the effectiveness of naturopathic remedies should not be underestimated. Although the women of this study indicated that their satisfaction with naturopathy at menopause was profoundly related to the manner in which their health status was diagnosed and treatment was administered, several informants stated that they would not use naturopathy for treatment of menopause signs if the treatment didn't work. Dietary and exercise regimens, herbal remedies, stress management techniques, counseling, use of plant extracts containing estrogen compounds, and prescription of natural and synthetic hormones by naturopathic physicians provided women with relief from troubling menopause signs. Quantitative evaluation of these therapies should be encouraged. 
Summary

Several of the informants reported using and intending to continue to use both conventional and naturopathic health care. The women of this study are informed consumers of health care and recognize that some health matters can be resolved satisfactorily with conventional medicine, while other health matters may be appropriately treated with alternative medicine. Unfortunately, many barriers exist in the United States for patients wishing to select alternative health care. Studying attitudes toward healing systems in societies that exhibit a greater acceptance of alternative medicines would assist in gaining perspective on societal influences that shape the health care climate in the United States. In China, for example, traditional Chinese medicine and conventional Western medicine are integrated into the health care system (Roemer, 1985) and individuals utilize both types of medicine according to perceived appropriateness to the presenting condition. Continued examination of the social and political context of health and alternative medicine will contribute to the development of policy that addresses alternative medicine utilization. "Any system of medicine is practised within a social and political context and involves inter-personal transactions of a more or less institutional nature. These social dimensions are as much a part of medical practice as clinical knowledge” (Sharma, 1992, p. 1).

The grounded theory methodology used in this study enabled identification of conditions leading to the use of naturopathy at menopause and assisted in formulating theory about how these conditions relate to interpersonal and intrapersonal interactions and strategies associated with selection of a health care provider. Grounded theory methodology would be of further use in exploring other aspects of menopausal health care. For example, in our modern Western societies it is increasingly common to find women who, while experiencing the menopausal transition, are contending with busy careers and 
young children. These women may have little time or inclination to pay attention to their personal and environmental changes, practice natural self-care, or peruse information about menopause. A qualitative investigation of the experience of menopausal women who use and are satisfied with conventional health care and hormone replacement therapy might contribute additional theory about options in health care at menopause.

Grounded theory methodology might also be used to understand patients' selection of alternative medicine for health matters other than menopause. As the menopause experience was integral to the development of the grounded theory in this study, the illness experience will be integral to the development of further qualitative investigations of alternative medicine. These studies could set the groundwork for quantitative investigation of alternative therapies. For example, identifying, measuring and comparing aspects of the grounded theory generated in this study (such as natural self-care practices or informational exchanges) in samples of alternative medicine users and conventional medicine users might further refine theory about use of alternative medicine.

According to the naturopathic philosophy of health, illness reflects an imbalance between the individual and the wider world (Sutherland, 1988). Menopause, though not an illness, is also a result of both biological and sociocultural imbalances. Naturopathy, which strives to decrease these imbalances by stimulating the natural healing forces present in the human body, was selected for menopausal health care by the informants of this study because it allowed them to participate in this re-balancing process. Further, when naturopathic physicians prescribe hormone replacement therapy, they typically do so after extensive interaction with the patient to determine that HRT is the best treatment according to the patient's individual circumstances and experience of menopause.

In this study, women whose troubling menopause signs were not alleviated by naturopathic methods were satisfied with the naturopathic approach to health care, and were 
willing to continue to try to achieve positive results. Perhaps women who continued to experience unmanageable menopause signs in spite of naturopathic treatment will eventually utilize the conventional medical system for health care during menopause. Such phases of the utilization and treatment process are acceptable to these women because they progress in accordance with their experience of menopause.

Menopause is not a static state in need of change or reversal; it is a developmental process that sometimes requires management with assistance from a health care practitioner. For the women of this study, the outcome of naturopathic treatment of menopause signs was dependent on the process of diagnosis and treatment. Understanding patients' choice of therapy might be further served by studying illness as a process rather than a static state. Continued research may reveal how awareness of patients' values and beliefs can assist in determining appropriate treatment.

Reiser (1993) discusses "the emergence of an era that focuses on the experiences of individuals with illness to provide an alternative voice in health care" (p. 1012). The experiences of individuals with illness should be significant features of health care practice, education, research, and policy. Further, according to Reiser, the view that patients are benefited by medicine, but unable to help it, should be reversed. Women contributed their knowledge of alternative medicine and menopause to this research effort because they wanted all women to benefit from increased understanding of health care options at midlife. This study serves to deliver this knowledge to health professionals for the benefit of women now and in the future. 


\section{REFERENCES}

Achterberg, Jeanne (1990). Woman as healer. Boston: Shambhala.

Akerele, O. (1987). The best of both worlds: Bringing traditional medicine up to date. Social Science and Medicine, 42, 177-181.

Aldridge, D. (1990). The delivery of health care alternatives: Discussion paper. The Royal Society of Medicine, 83, 179-182.

Anderson, W., O'Connor, B.B., MacGregor, R.R., \& Schwartz, J.S. (1993). Patient use and assessment of conventional and alternative therapies for HIV infection and AIDS. AIDS, 7, 561-565.

Baum, M. (1987). Science versus non-science in medicine: Fact or fiction? The Royal Society of Medicine, 80, 332-333.

Beard, M.K. (1992). Atrophic vaginitis: Can it be prevented as well as treated? Postgraduate Medicine, 91 (6), 257-260.

Bell, S.E. (1987). Changing ideas: the medicalization of menopause. Social Science and Medicine, 24, 535-542.

Berkun, C.S. (1986). In behalf of women over 40: Understanding the importance of the menopause. Social Work, 31, 378-384.

Birge, S.J. \& Dalsky, G. (1989). The role of exercise in preventing osteoporosis. Public Health Reports Supplement, 104 (5), 54-58.

Boston Women's Health Book Collective (1984). The new our bodies, ourselves. New York: Simon \& Schuster.

Buck, M.M. \& Gottlieb, L.N. (1991). The meaning of time: Mohawk women at midlife. Health Care for Women International, 12, 41-50.

Calabrese, C. (1992). A plan for outcomes studies in unorthodox medicine: Turning differences into meaning. Unpublished manuscript. Bastyr College of Natural Heath Sciences, Seattle.

Cassileth, B.R., Lusk, E.J., Strouse, T.B., \& Bodenheimer, B.J. (1984). Contemporary unorthodox treatments in cancer medicine. Annals of Internal Medicine, 101, 105112.

Christie, V.M. (1991). A dialogue between practitioners of alternative (traditional) medicine and modern (Western) medicine in Norway. Social Science and Medicine, 32, 549-552.

Clark, C.S. (1992). Alternative medicine. Congressional Quarterly Inc. 2, 73-96. 
Cobleigh, M. A., Berris, R.F., Bush,T., Davidson, N.E., Robert, N.J., Sparano, J.A., Tormey, D.C., \& Wood, W.C. (1994). Estrogen replacement therapy in breast cancer survivors: A time for change. Journal of the American Medical Association, 272, 540-545.

Colditz, G.A., Stampfer, M.J., Willett, W.W., Hennekens, B.R., \& Speizer, F.E. (1990). Prospective study of estrogen replacement therapy and risk of breast cancer in postmenopausal women. Journal of the American Medical Association, $264,2648-2653$.

Cooksey, S.G., Imle, M.A., \& Smith, C.L. (1991). An inductive study of the transition of menopause. In Voda, A.M. \& Conover, R. (Eds.), Proceedings 8th Conference Society for Menstrual Cycle Research (pp. 75-111). Salt Lake City: The Society for Menstrual Cycle Research.

Dawson-Hughes, B., Dallal, G.E., Krall, E.A., Sadowski, L., Sahyoun, N.S., \& Tannenbaum, S. (1990). A controlled trial of the effect of calcium supplementation on bone density in postmenopausal women. The New England Journal of Medicine, 323, 878-883.

Dickson, G.L. (1990a). A feminist poststructuralist analysis of the knowledge of menopause. Advances in Nursing Science, 12 (3), 15-31.

Dickson G.L. (1990b). The metalanguage of menopause research. Image, 22, 168-173.

Ditkoff, E.C., Crary, W.G.., Cristo, M., \& Lobo, R.A., (1991). Estrogen improves psychological function in asymptomatic postmenopausal women. Obstetrics \& Gynecology, 78, 991-995.

Donnelly, W.J., Spykerboer, J.E., \& Thong, Y.H. (1985). Are patients who use alternative medicine dissatisfied with orthodox medicine? The Medical Journal of Australia, 142, 539-541.

Doress, P.B. \& Siegal, D.L. (1987). Ourselves, growing older. New York: Simon \& Schuster.

Draper, J. \& Roland, M. (1990). Perimenopausal women's views on taking hormone replacement therapy to prevent osteoporosis. British Medical Journal, 300, 786-788.

Edlin, G. \& Golanty, E. (1985). Health \& Wellness. Portola Valley, CA: Jones and Bartlett.

Egeland, G.M., Matthews, K.A., Kuller, L.H., \& Kelsey, S.F. (1988). Characteristics of noncontraceptive hormone users. Preventive Medicine, 17, 403-411.

Eisenberg, D.M., Kessler, R.C., Foster, C., Norlock, F.E., Calkins, D.R., \& Delabanco, T.L. (1993). Unconventional medicine in the United States. The New England Journal of Medicine, 328, 246-252. 
Engel, N.S. (1987). Menopausal stage, current life change, attitude toward women's roles, and perceived health status. Nursing Research, 36, 353-357.

Ferguson, K.J., Hoegh, C., \& Johnson, S. (1989). Estrogen replacement therapy: a survey of women's knowledge and attitudes. Archives of Internal Medicine, 149, 133-136.

Filips, J. (1993, September 19). Change of heart. The Oregonian, p. LO1.

Flint, M. (1975). The menopause: Reward or punishment? Psychosomatics, 16, 161163.

Furnham, A. \& Smith, C. (1988). Choosing alternative medicine: A comparison of the beliefs of patients visiting a general practitioner and a homeopath. Social Science and Medicine, 26, 685-689.

Gambrell, R.D., Maier, R.C., \& Sanders, B.I. (1983). Decreased incidence of breast cancer in postmenopausal estrogen-progestogen users. Obstetrics \& Gynecology, $62,435-443$.

Gannon, L.G. (1988). The potential role of exercise in the alleviation of menstrual disorders and menopausal symptoms: a theoretical synthesis of recent research. Women \& Health, 14 (2), 105-127.

George, T. (1988). Menopause: Some interpretations of the results of a study among a non-Western group. Maturitas, 10, 109-116.

Gergen, M.M. (1990). Finished at 40: Women's development within the patriarchy. Psychology of Women Quarterly, 14, 471-493.

Germaine, L.M. \& Freedmen, R.R. (1984). Behavioral treatment of menopausal hot flashes: Evaluation by objective methods. Journal of Consulting and Clinical Psychology, 52, 1072-1079.

Glaser, B.G. (1978). Theoretical sensitivity: Advances in the methodology of grounded theory. Mill Valley, CA: Sociology Press.

Glaser, B.G. \& Strauss, A.L. (1967). The discovery of grounded theory: Strategies for qualitative research. New York: Aldine de Gruyter.

Goodman, M.J. (1982). A Critique of menopause research. In A.M. Voda \& M. Dinnerstein, (Eds.), Changing perspectives on menopause. (pp. 273-288). Austin: University of Texas Press.

Greenwood, S. (1984). Menopause, Naturally. Volcano: Volcano Press.

Hammar, M., Berg, G., \& Lindgren, R. (1990). Does physical exercise influence the frequency of postmenopausal hot flushes? ACTA Obstetricia et Gynecologica Scandinavica, 69, 409-412. 
Hemminki, E., Malin, M. \& Topo, P. (1993). Selection to postmenopausal therapy by women's characteristics. Journal of Clinical Epidemiology, 46, 211-219.

Henrich, J.B. (1992). The postmenopausal estrogen/breast cancer controversy. Journal of the American Medical Association, 268, 1900-1902.

Hesse-Biber, S., Kinder, T.S., Dupuis, P.R., \& Tornabene, E. (1991-1992). HyperResearch [computer program]. Randolph, MA: Researchware, Inc.

Hewer, W. (1983). The relationship between the alternative practitioner and his patient: A review. Psychotherapy and Psychosomatics, 40, 172-180.

Holmes, M.M., Rovner, D.R., Rothert, M.L., Elstein, A.S., Holzman, G.B., Hoppe, R.B., Metheny, W.P., \& Rabitch, M.M. (1987). Women's and physicians' utilities for health outcomes in estrogen replacement therapy. Journal of General Internal Medicine, 2, 178-182.

Hudson, T. (1992). Gynecology and naturopathic medicine: A treatment manual. Beaverton, OR: P.K. Publishers.

Hudson, T., Bettenberg, R., Breed, C., Dalen, C., Standish, L., Noé, J., O’Donnell, T., \& Dibble, E. (1993, September). Clinical and endocrinological effects of a menopausal botanical formula. Study presented at the National Naturopathy Convention, Portland, OR.

Hunt, K. (1988). Perceived value of treatment among a group of long-term users of hormone replacement therapy. Journal of the Royal College of General Practitioners, 38, 398-401.

Hunter, M.S., (1990). Somatic experience of the menopause: A prospective study. Psychosomatic Medicine, 52, 357-367.

Jensen, P. (1990). Alternative therapy for atopic dermatitis and psoriasis: Patient-reported motivation, information source and effect. ACTA Dermato-Venereologica, 70 , 425-428.

Jingfeng, C. (1987). Toward a comprehensive evaluation of alternative medicine. Social Science and Medicine, 25, 659-667.

Kaufert, P. A. (1980). The perimenopausal woman and her use of health services. Maturitas, 2, 191-205.

Kaufert, P.A. \& Gilbert, P. (1986). Women, menopause, and medicalization. Culture, Medicine, \& Psychiatry, 10, 7-21.

Kaufert, P. \& Syrotuik, J. (1981). Symptom reporting at the menopause. Social Science and Medicine, 15E, 173-184.

Kleijjnen, J., Knipschild, P., \& Riet ter, G. (1991). Clinical trials of homeopathy. British Medical Journal, 302, 316-323. 
Køster, A. (1991). Change-of-life anticipations, attitudes, and experiences among middleaged Danish women. Health Care for Women International, 12, 1-13.

Leiblum, S.R. \& Swartzman, L.C. (1986). Women's attitudes toward the menopause: an update. Maturitas, 8, 47-56.

Lichtman, R. (1991). Perimenopausal hormone replacement therapy: Review of the literature. Journal of Nurse-Midwifery, 36, 30-48.

Lincoln, Y.S. \& Guba, E.G. (1985). Naturalistic Inquiry. Newbury Park: Sage.

Lindsay, R. (1989). Alternative strategies for prevention of postmenopausal osteoporosis. Public Health Reports Supplement, 104 (5), 66-70.

Lloyd, P., Lupton, D., Wiesner, D., \& Hasleton, S. (1993). Choosing alternative therapy: An exploratory study of sociodemographic characteristics and motives of patients resident in Sydney. Australian Journal of Public Health, 17, 135-143.

Lock, M. (1982). Models and practice in medicine: Menopause as syndrome or life transition? Culture, Medicine, \& Psychiatry, 6, 261-280.

Locke, L.F., Spirduso, W.W., \& Silvermen S.J. (1993). Proposals that work (3rd ed.). Newbury Park, CA: Sage.

Logothetis, M.L. (1991). Women's decisions about estrogen replacement therapy. Western Journal of Nursing Research, 13, 458-474.

MacPherson, K.I. (1985). Osteoporosis and menopause: A feminist analysis of the social construction of a syndrome. Advances in Nursing Science, 7 (4), 11-22.

MacPherson, K. (1991). Hormone replacement therapy for menopause: A contrast between medical and women's health movement perspectives. In Voda, A.M. \& Conover, R. (Eds.), Proceedings 8th Conference Society for Menstrual Cycle Research (pp. 196-208). Salt Lake City: The Society for Menstrual Cycle Research.

Mahaney, F.K. (1992). Unconventional methods under review by NIH. Journal of the National Cancer Institute, 84, 1067.

Mansfield P.K. (1992). Midlife women and menopause: A challenge for the mental health counselor. Journal of Mental Health Counseling, 14, 73-83.

Mansfield, P.K., Jorgensen, C.M., \& Yu, L. (1989) The menopausal transition: guidelines for researchers. Health Education, 20 (6), 44-49.

Martin, E. (1988). Medical metaphors of women's bodies: Menstruation and menopause. International Journal of Health Services, 18, 237-254).

Martin, M.C., Block, J.E., Sanchez, S.D., Arnaud, C.D., \& Beyene, Y. (1993). Menopause without symptoms: The endocrinology of menopause among rural Mayan Indians. American Journal of Obstetrics and Gynecology, 168, 1839-45. 
Marwick, C (1992). Congress wants alternative therapies studied; NIH responds with programs. Journal of the American Medical Association, 268, 957-958.

Matthews, K.A. (1992). Myths and realities of the menopause. Psychosomatic Medicine, 54, $1-9$.

Matthews, K.A., Wing, R.R., Kuller, L.H., Meilahn, E.M., Kelsey, S.F., Costello, E.J., Caggiula, A.W. (1990). Influences of natural menopause on psychological characteristics and symptoms of middle-aged healthy women. Journal of Consulting and Clinical Psychology, 58, 345-351.

McCann, D.P. \& Blossom, J. (1990). The physician as a patient educator: From theory to practice. Western Journal of Medicine, 153, 44-49.

McClain, C.S. (1989). Women as healers: Cross-cultural perspectives. New Brunswick: Rutgers University Press

McCrea, F.B. (1983). The politics of menopause: The "discovery" of a deficiency disease. Social Problems, 31, 111-123.

McElmurry, B.J. \& Huddleston, D.H. (1991). Self-care and menopause: Critical review of research. Health Care for Women International, 12, 15-26.

McGinnis, L.S. (1991). Alternative therapies, 1990. Cancer, 67 (Supplement). 17881792.

McKee, J. (1988). Holistic health and the critique of Western medicine. Social Science and Medicine, 26, 775-784.

McKeever, L.C. (1991). Informal models of women's perimenopausal experiences: Implications for health care. In Voda, A.M. \& Conover, R. (Eds.), Proceedings 8th Conference Society for Menstrual Cycle Research (pp. 232-255). Salt Lake City: The Society for Menstrual Cycle Research.

McKinlay, J.B., McKinlay, S.M., \& Brambilla, D.J. (1987a). Health status and utilization behavior associated with menopause. American Journal of . Epidemiology, 125 (1), 110-121.

McKinlay, J.B., McKinlay, S.M., \& Brambilla, D.J. (1987b). The relative contributions of endocrine changes and social circumstances to depression in mid-aged women. Journal of Health and Social Behavior, 28, 345-363.

Mervis, H. (1992). NIH makes room for the unconventional after congress mandates new programme. Nature, $358,5$.

Miller, K.L. (1992). Alternatives to estrogen for menopausal symptoms. Clinical Obstetrics and Gynecology, 35, 884-893.

Montbriand, M.J. (1993). Freedom of Choice: An issue concerning alternate therapies chosen by patients with cancer. Oncology Nursing Forum, 20, 1195-1201. 
Montbriand, M.J. \& Laing, G. (1991). Alternative health care as a control strategy. Journal of Advanced Nursing, 16, 325-332.

Murray, J. \& Shepherd, S. (1993). Alternative or additional medicine? An exploratory study in general practice. Social Science and Medicine, 37, 983-988.

Murray, M.T. \& Pizzorno, J.E. Jr. (1990). An encyclopedia of natural medicine. Rocklin, CA: Prima Publishing.

National College of Naturopathic Medicine-a (not dated). Academic Brochure (Promotional literature). Portland Naturopathic Clinic: Portland, Oregon.

National College of Naturopathic Medicine-b (not dated). Naturopathic management of menopause (Promotional literature). Portland Naturopathic Clinic: Portland, Oregon.

National Women's Health Network (1989). Taking hormones and women's health: Choices, risks, benefits. Washington: National Women's Health Network.

NIH Office of Alternative Medicine (1994). Fact sheet \#2: Research programs. NIH, Bethesda MD.

Northcott, H.C. \& Bachynsky, J.A. (1993). Concurrent utilization of chiropractic, prescription medicines, nonprescription medicines and alternative health care. Social Science and Medicine, 37, 431-435.

Notelovitz, M. (1987). Climacteric Medicine: Cornerstone for midlife health and wellness. Public Health Reports Supplement, 102 (4), 116-124.

Notman, M. (1979). Midlife concerns of women: Implications of the menopause. American Journal of Psychiatry, 136, 1270-1274.

Ojeda, L. (1992). Menopause without medicine. Alameda: Hunter House.

O'Neill, P. (1993, September 25). Prognosis for alternative health care? The Oregonian, p. A01

Osujih, M. (1993). Exploration of the frontiers of tradomedical practices: Basis for development of alternative medical healthcare services in developing countries. Journal of the Royal Society of Health, 113, 190-194.

Patel, M.S. (1987a). Evaluation of holistic medicine. Social Science and Medicine, 24, $169-175$.

Patel, M.S. (1987b). Problems in the evaluation of alternative medicine. Social Science and Medicine, 25, 669-678.

Patton, M.Q. (1990). Qualitative evaluation and research methods. Newbury Park, CA: Sage. 
Pietroni, P.C. (1992). Beyond the boundaries: Relationship between general practice and complementary medicine. British Medical Journal, 305, 564-566.

Prince, L.R., Smith, M., Dick, I.M., Price, R.I., Webb, P.G., Henderson, N.K., \& Harris, M.M. (1991). Prevention of postmenopausal osteoporosis: A comparative study of exercise, calcium supplementation, and hormone-replacement therapy. New England Journal of Medicine, 325, 1189-1195.

Quinn, A.A. (1990). A theoretical model of the perimenopausal process. Journal of Nurse-Midwifery, 36, 25-29.

Roemer, M.I. (1985). National Strategies for Health Care Organization. Ann Arbor, MI: Health Administration Press.

Reiser, S.J. (1993). The era of the patient: Using the experience of illness in shaping the missions of health care. Journal of the American Medical Association, 269, 10121017.

Schmitt, N., Gogate, J., Rothert, M., Rovner, D., Holmes, M., Talarcyzk, G., Given, B., \& Kroll, J. (1991). Capturing and clustering women's judgment policies: The case of hormonal therapy for menopause. Journal of Gerontology, 46 (3), P92P101.

Semla, T.P. \& Parent, L.S. (1990). Additional benefits and risk of HRT for osteoporosis. Drug Topics, 134 (3), 68-79.

Shangold, M.M. (1990). Exercise in the menopausal woman. Obstetrics \& Gynecology, 75 (4) (Supplement), 53S-58S.

Sharma, U. (1992). Complementary medicine today. New York: Tavistock/Routledge.

Sheehy, G. (1992). Menopause: The silent passage. New York: Random House.

Sillero-Arenas, M., Delgado-Rodriguez, M., Rodigues-Canteras, R., Bueno-Cavanillas, A., \& Galvez-Vargas, R. (1992). Obstetrics and Gynecology, 79, 286-294.

Smart, H.L., Mayberry, J.F., \& Atkinson, M. (1986). Alternative medicine consultations and remedies in patients with the irritable bowel syndrome. Gut, 27, 826-828.

Stampfer, M.J., \& Colditz, C.A. (1991). Estrogen replacement therapy and coronary heart disease: A qualitative assessment of the epidemiologic evidence. Preventive Medicine, 20, 47-63.

Strauss, A.L. (1987). Qualitative analysis for social scientists. Cambridge: Cambridge University Press.

Strauss, A. \& Corbin, J. (1990). Basics of qualitative research: Grounded theory procedures and techniques. Newbury Park: Sage.

Sutherland, L.R. (1988). Alternative medicine: What are our patients telling us? [Editorial] American Journal of Gastroenterology, 83, 1154-1157. 
Thomas, K.J., Carr, J., Westlake, L., Williams, B.T. (1991). Use of non-orthodox and conventional health care in Great Britain. British Medical Journal, 302, 207-210.

Tonkin, R.D. (1987). Role of research in the rapprochement between conventional medicine and complementary therapies: discussion paper. Journal of the Royal Society of Medicine, 80, 361-363.

Ussher, J.M. (1992). Research and theory related to female reproduction: Implications for clinical psychology. British Journal of Clinical Psychology, 31, 129-151.

Visser, G.J., Peters, L., \& Rasker, J.J. (1992). Rheumatologists and their patients who seek alternative care: An agreement to disagree. Journal of Rheumatology, 3l, 485-490.

Voda, A.M. (1992). Menopause: A normal view. Clinical obstetrics and Gynecology, 35 (4), 923-933.

Weed, S.S. (1992). Menopausal years: The wise woman way. Woodstock, NY: Ash Tree.

West, C. (1993). Reconceptualizing gender in physician-patient relationships. Social Science and Medicine, 36, 57-66.

Williams, K. (1994, October 9). Lifestyle pioneers. The Eugene Register-Guard, p. 1F.

Wilson, R.A. (1966). Feminine forever. New York: M. Evans.

Young, R.L., Kumar, N.S., \& Goldzieher, J.W. (1990). Management of menopause without estrogen. Drugs, 40, 220-230.

Zhang, J., Feldblum, P.J., \& Fortney, J.A. (1992). Moderate physical activity and bone density among perimenopausal women. American Journal of Public Health, 82, 736-738. 


\section{APPENDIX A \\ INVITATION TO PARTICIPATE}

Dorothy Tibbetts

Graduate Student

Department of Public Health Education

Portland State University

date

Informant

Informant's address

Dear Informant:

Menopause is a time when a woman must make several important health care choices. Research concerning menopause has relied heavily upon the characteristics of women who attend conventional medical clinics. We don't hear enough from women who have used alternative health care.

I am studying women's experiences of naturopathic health care during their menopausal transition. To be successful in my effort, I am seeking your assistance. Your name was provided to me by Dr. at the Clinic. Primary information for my study will be obtained by conducting interviews with women like you. I am very interested in learning about your experience of naturopathic health care and of menopause. Your participation in this project will provide valuable information which will help to provide ongoing education to women about health care options during the menopausal transition.

I would like to talk with you about your experiences sometime during June or July. Interviews will take no more than one hour and will occur at a place that is convenient for you which we can arrange by phone. I may wish to follow-up with an additional short interview which would occur no later than August 31 st.

If you would like to participate, please drop the enclosed postcard in the mail, or give me (Dorothy) a call at 236-4026, day or evening. We can then set up an appointment. Should you have any questions or concerns, please call me at any time. The enclosed consent form contains additional information about the project.

I hope to be hearing from you soon!

Sincerely,

Dorothy Tibbetts

Graduate Student

Public Health Education 


\section{APPENDIX B}

\section{CONSENT FORM}

Women who choose naturopathic health care during the menopausal transition: A study in grounded theory

I, , agree to take part in this research project about women's experience of naturopathic health care during the menopausal transition. I have been chosen to participate on the basis of my association with the

Clinic. I understand that the study involves at least one in-person, in-depth interview with the principle investigator, Dorothy Tibbetts, who will tape record the interview session. The primary interview session will last up to 1 hour, and follow-up phone calls or additional short, in-person interviews may be conducted for the duration of the research period ending August 31, 1994. Dorothy Tibbetts has told me that the purpose of the study is to learn more about why some women choose naturopathy for menopause-related health care. I may not receive any direct benefit from taking part in this study, but the study may help to increase knowledge that may help others in the future. Dorothy Tibbetts has offered to answer any questions I have about the study and what I am expected to do. I may call her at 236-4026 at any time during the duration of the study if I have additional questions. She has promised that all information I give will be kept confidential to the extent permitted by law, and that the names of all people in the study will remain anonymous. I understand that I do not have to take part in this study, and that if I discontinue participation at any time it will not affect my relationship with any educational or medical facility which may be associated with this study.

I have read and understand the above information and agree to take part in this study.

Date: Signature:

If you have concerns or questions about this study, please contact the Chair of the Human Subjects Research Review Committee, Office of Grants and Contracts, 105 Neuberger Hall, Portland State University, 503-725-3417. 


\section{APPENDIX C \\ PARTICIPANT INFORMATION FORM}

Name

Age

Address

City/State/Zip

Telephone (home)

(work)

Ethnic background (circle one):

Caucasian

African American

Native American

Asian American

Hispanic

Other

Education (circle highest degree obtained):

High School

2-Year College

4-Year College

Masters

Doctorate

Other

Yearly Income before taxes (circle one):

$$
\begin{aligned}
& \text { under } \$ 10,000 \\
& 10,000-20,000 \\
& 20,000-30,000 \\
& 30,000-40,000 \\
& 40,000-50,000 \\
& \text { over } 50,000
\end{aligned}
$$

When was your last period?

Have you had a hysterectomy? if so, when?

Have you had an oophorectomy? if so, when?

Please indicate the other kinds of alternative treatments you use (that are not provided by your naturopathic physician) by marking the blank beside that treatment: Chiropractic Acupuncture Homeopathy Bodywork (i.e. Massage, Shiatsu, Rolfing, Feldenkreis, etc.) Other (please identify)

Do you have an insurance policy that covers naturopathic health care?

When did you last visit a naturopathic physician for menopause-related health care? 


\section{APPENDIX D \\ INTTIAL INTERVIEW GUIDE}

Greetings.

Read/complete consent form.

Discuss/complete background information form.

1. Tell me how it happened that you initially decided to seek naturopathic treatment.

- As you understand it, what is the philosophy of the naturopathic approach to health care?

- Did you understand this philosophy when you first started using naturopathy?

- Did this understanding influence your decision to seek naturopathic health care initially?

- Will you continue to use naturopathy? Why?/Why not?

2. Which menopausal signs do/did you experience?

- Please describe any positive aspects of menopause you may have experienced. What was your response to this experience?

- Please describe any negative aspects of menopause you may have experienced. What was your response to this experience?

3. Why did you decide to seek naturopathic treatment for your menopausal signs?

4. Describe the treatment you are receiving (or have received) for menopausal health care from your naturopathic physician.

- What are the results you have experienced so far?

- Are you satisfied with the treatment? Why?

- Are you satisfied with the results? Why?

- What were your expectations of naturopathic treatment for menopausal signs?

5. Are you now receiving or have you ever received treatment for menopausal health care from a conventional physician?

- Describe the treatment you are receiving (or have received) for menopausal health care from your conventional physician.

- What are the results you have experienced so far?

- Are you satisfied with the treatment? Why?

- Are you satisfied with the results? Why?

- What were your expectations of conventional treatment for menopausal signs?

- Are you still seeing a conventional physician for menopausal health care? Why?/Why did you stop?

- Do/did you tell your conventional physician that you use/used naturopathic medicine for your menopause-related health care? Why/why not?

- Have you told your naturopathic physician that you did receive/are receiving care from a conventional physician for menopause-related health care? Why/why not?

- What is it like receiving treatment for menopausal health care from both a conventional physician and a naturopathic physician? 


\section{APPENDIX D (CONTINUED)}

INITIAL INTERVIEW GUIDE

6. What does menopause mean to you? (Does menopause have any special significance for you?)

- Is menopause a time when medical treatment should be sought?

- Is menopause a natural life transition?

- In general, is menopause a positive or a negative experience?

7. Tell me about how you learned about menopause. Did this way of learning about menopause influence your expectations of menopause?

- Has your actual experience of menopause been the same as what you expected?

- Please describe how your expectations were the same as/differed from your actual experience of menopause.

Do you have any questions that I may be able to answer? 


\title{
APPENDIX E
}

\section{FINAL INTERVIEW GUIDE}

\author{
Greetings. \\ Read/complete consent form. \\ Discuss/complete background information form.
}

1. Tell me how it happened that you initially decided to seek naturopathic treatment for menopause-related health care?

- Will you continue to use naturopathy? Why?/Why not?

2. Which menopausal signs do/did you experience?

- Please describe any positive aspects of menopause you may have experienced. What was your response to this experience?

- Please describe any negative aspects of menopause you may have experienced. What was your response to this experience?

- Were the signs you experienced expected? Unexpected?

3. Why did you decide to seek naturopathic treatment for your menopausal signs?

- If you didn't want to use HRT, why not continue to see conventional MD but just not use HRT?

4. Describe the treatment you are receiving (or have received) for menopausal health care from your naturopathic physician.

- What are the results you have experienced so far?

- Are you satisfied with the treatment? Why?

- Are you satisfied with the results? Why?

- Did the treatment work right away? Did it take time to work?

5. Are you now receiving or have you ever received treatment for menopausal health care from a conventional physician?

- Describe the treatment you are receiving (or have received) for menopausal health care from your conventional physician.

- What are the results you have experienced so far?

- Are you satisfied with the treatment? Why?

- Are you satisfied with the results? Why?

- Are you still seeing a conventional physician for menopausal health care? Why?/Why did you stop?

- Do/did you tell your conventional physician that you use/used naturopathic medicine for your menopause-related health care? Why/why not?

- Have you told your naturopathic physician that you did receive/are receiving care from a conventional physician for menopause-related health care? Why/why not?

- What is it like receiving treatment for menopausal health care from both a conventional physician and a naturopathic physician?

- Have you ever used hormone replacement therapy?

- Are you satisfied with the level of communication you share with your conventional physician? 


\section{APPENDIX E (CONTINUED)}

\section{FINAL INTERVIEW GUIDE}

6. What does menopause mean to you? (Does menopause have any special significance for you?)

- What did your experiences of menopause mean to you in the beginning?

- What do your experiences of menopause mean to you now?

- Why has that meaning changed?

- In general, is menopause a positive or a negative experience?

- Is it a time for quieting?

- Interrelatedness?

- Individual?

7. Tell me about how you learned about menopause. Did this way of learning about menopause influence your expectations of menopause?

- Has your actual experience of menopause been the same as what you expected?

- Please describe how your expectations were the same as/differed from your actual experience of menopause.

- What are the sources of your information?

8. Suppose a woman younger than you, experiencing similar menopausal signs (as you have explained to me), came to you for assistance in seeking menopause-related health care. What would you recommend?

9. How did it come about that you have the health values you have described to me?

Do you have any questions that I may be able to answer? 